\title{
SUPPLY-SIDE DRUG POLICY IN THE PRESENCE OF SUBSTITUTES: EVIDENCE FROM THE INTRODUCTION OF ABUSE-DETERRENT OPIOIDS
}

\author{
Abby Alpert \\ David Powell \\ Rosalie Liccardo Pacula \\ Working Paper 23031 \\ http://www.nber.org/papers/w23031 \\ NATIONAL BUREAU OF ECONOMIC RESEARCH \\ 1050 Massachusetts Avenue \\ Cambridge, MA 02138 \\ January 2017
}

We would like to thank seminar participants at the Conference of the American Society of Health Economists and the APPAM Fall Research Conference for helpful comments, especially from our discussants Dean Lillard and Melinda Buntin. The views expressed herein are those of the authors and do not necessarily reflect the views of the National Bureau of Economic Research.

NBER working papers are circulated for discussion and comment purposes. They have not been peer-reviewed or been subject to the review by the NBER Board of Directors that accompanies official NBER publications.

(C) 2017 by Abby Alpert, David Powell, and Rosalie Liccardo Pacula. All rights reserved. Short sections of text, not to exceed two paragraphs, may be quoted without explicit permission provided that full credit, including $\odot$ notice, is given to the source. 
Supply-Side Drug Policy in the Presence of Substitutes: Evidence from the Introduction of Abuse-Deterrent Opioids

Abby Alpert, David Powell, and Rosalie Liccardo Pacula

NBER Working Paper No. 23031

January 2017

JEL No. I12,I18,K42

\title{
ABSTRACT
}

Overdose deaths from prescription opioid pain relievers nearly quadrupled between 1999 and 2010, making this the worst drug overdose epidemic in U.S. history. In response, numerous supply-side interventions have aimed to limit access to opioids. However, these supply disruptions may have the unintended consequence of increasing the use of substitute drugs, including heroin. We study the consequences of one of the largest supply disruptions to date to abusable opioids - the introduction of an abuse-deterrent version of OxyContin in 2010. Our analysis exploits across state variation in exposure to the OxyContin reformulation. Using data from the National Survey on Drug Use and Health (NSDUH), we show that states with higher pre-2010 rates of OxyContin misuse experienced larger reductions in OxyContin misuse, permitting us to isolate consumer substitution responses. We estimate large differential increases in heroin deaths immediately after reformulation in states with the highest initial rates of OxyContin misuse. We find less evidence of differential reductions in overall opioid-related deaths, potentially due to substitution towards other opioids, including more harmful synthetic opioids such as fentanyl. Our results imply that a substantial share of the dramatic increase in heroin deaths since 2010 can be attributed to the reformulation of OxyContin.

\author{
Abby Alpert \\ The Wharton School \\ University of Pennsylvania \\ 3641 Locust Walk \\ Philadelphia, PA 19104 \\ alpertab@wharton.upenn.edu \\ David Powell \\ RAND Corporation \\ 1776 Main Street \\ P.O. Box 2138 \\ Santa Monica, CA 90407 \\ powelld@nber.org
}

\author{
Rosalie Liccardo Pacula \\ RAND Corporation \\ 1776 Main Street \\ P.O. Box 2138 \\ Santa Monica, CA 90407-2138 \\ and NBER \\ pacula@rand.org
}




\section{Introduction}

Drug overdose deaths have increased dramatically over the past 15 years, increasing by 137\% between 2000 and 2014 (Rudd et al., 2016). By 2009, they were the leading cause of death from injuries in the United States, exceeding deaths from motor vehicle accidents and firearms (Paulozzi, 2012). Overdose deaths from prescription opioid pain relievers have been the primary driver behind this upward trend, nearly quadrupling since 1999 and killing nearly 19,000 individuals in 2014 (CDC, 2016). This unprecedented rise in opioid overdose deaths has prompted the Centers for Disease Control and Prevention (CDC) to call this the worst drug overdose epidemic in U.S. history (Kolodny, et al., 2015). While prescription opioids serve a legitimate medical purpose in the treatment of pain (see American Pain Society (2009) for a review), they are also highly addictive and present a serious risk for abuse, dependence, and overdose. The harmful effects of prescription opioids are particularly acute in the U.S.- the largest consumer of these drugs. ${ }^{1}$ In 2014, nearly 2 million Americans abused or were dependent on prescription opioids, and 10.3 million had used prescription opioids for nonmedical purposes in the past year (SAMHSA, 2015). The economic costs of opioid abuseincluding health care and criminal justice costs as well as productivity loss — are also large, estimated at \$78.5 billion in 2013 (Florence et al., 2016).

Given the severity of the opioid epidemic, the federal government and states have implemented a vast array of policies aimed at curbing prescription opioid abuse. These policies have disproportionately targeted the supply-side of the market by limiting access to opioids, including Prescription Drug Monitoring Programs (PDMPs), Medicaid Lock-In Programs, pain clinic laws, enhanced diversion control, black box warnings, and abuse-deterrent drug formulations. This emphasis on supply-side interventions is consistent with the National Drug Control Strategy of the United States more broadly, which allocates the majority of its budget to enforcement and market disruption efforts. ${ }^{2}$ In contrast, less attention and funding have been directed to demand-side interventions, such as prevention and substance abuse treatment, ${ }^{3}$ which

\footnotetext{
${ }^{1}$ The U.S. consumes more than $80 \%$ of the world supply of oxycodone and $99 \%$ of hydrocodone-the main ingredients in the majority of prescription opioids (International Narcotics Control Board, 2008).

2 https://www.whitehouse.gov/sites/default/files/ondcp/about-content/fy2015_summary.pdf (accessed May 29, 2016)

${ }^{3}$ Prevention reduces the rate of new abuse while treatment attempts to reduce abuse among current users.
} 
aim to reduce the prevalence of addiction. Although, the recently signed $21^{\text {st }}$ Century Cures Act will provide $\$ 1$ billion in funding for these types of programs. ${ }^{4}$

While supply-side interventions often dominate the discussion surrounding drug policy, evidence of their effectiveness is mixed with many studies finding limited effects across a wide range of drugs (see for example, Dobkin and Nicosia, 2009; Dobkin et al., 2014; Pollack and Reuter, 2014). The failure of supply-side interventions can often be attributed to the presence of substitutes, which limits the scope for these policies to reduce overall drug abuse, even when successfully targeting one drug or one component of the supply chain. There are two types of potential substitution responses to supply-side policies which may lessen their efficacy. First, disruption of part of the supply chain for a given drug may lead to substitution across suppliers, which enables the continued production or distribution of the drug. Second, consumers may substitute across similar drugs. Previous evidence has shown fluid substitution across drugs in response to supply changes, with an emphasis on alcohol, smoking, and marijuana (e.g., DiNardo and Lemieux, 2001; Crost and Guerrero, 2012). While this evidence shows that there is substitution across some drugs, the policy implications of this type of substitution are not wellunderstood.

In this paper, we study the consequences of a massive nationwide supply disruption for opioid abuse: the introduction of abuse-deterrent OxyContin. In 2010, the FDA approved a reformulated, abuse-deterrent version of OxyContin which was designed to make the pill difficult to crush or dissolve. The most dangerous and addictive methods of abuse occur when OxyContin is crushed for ingestion, inhalation or injection to release the drug more quickly. The original formulation was then discontinued, marking a substantial reduction in the supply of abusable prescription pain relievers. At the time of the reformulation, OxyContin was one of the highest selling prescription drugs in the U.S. (ranking $15^{\text {th }}$ in terms of retail sales in 2010 (Bartholow, 2011)) and it was also one of the leading drugs of abuse due to the efficiency through which the pill could deliver highly concentrated amounts of oxycodone (Cicero et al., 2005). In fact, many experts have implicated OxyContin as one of the key causes of the opioid epidemic, as its introduction in 1996 coincided with the origin of the epidemic in the mid-1990s (e.g., Kolodny et al., 2015). The reformulation of OxyContin— the first prescription drug to

\footnotetext{
${ }^{4}$ In addition, the Comprehensive Addiction and Recovery Act (signed into law on July 22, 2016) budgeted \$181 million annually to address the opioid epidemic, including resources to expand prevention and addiction services.
} 
ever receive an abuse-deterrent designation by the FDA - represents a highly innovative approach to addressing the trade-off between preserving the medical benefits of opioids for legitimate pain patients (who take the pill orally) and limiting spillovers to non-medical use. Indeed, time series evidence suggests that the OxyContin reformulation significantly reduced non-medical OxyContin use by as much as 40\% (Cicero, et al. 2012; Butler, et al. 2013; Cicero, et al. 2015).

However, by raising the cost of OxyContin abuse, this intervention may have also had the unintended effect of increasing the abuse of substitute drugs, including even more harmful opiates such as heroin and fentanyl. To the extent that this occurred, it would reduce the effectiveness of the intervention in reducing overall drug abuse. While prescription opioids and heroin are pharmacologically similar, this relationship does not inherently imply that individuals will switch to the more dangerous illegal substance given the additional costs associated with acquiring and abusing illegal drugs. ${ }^{5}$ The existence and magnitude of actual substitution patterns across different types of drugs are determined by individual characteristics as well as access to substitutes, and therefore is an empirical question.

We examine this question in this paper by quantifying how the OxyContin reformulation impacted both OxyContin misuse and substitution from OxyContin to other drugs. By studying a unique supply disruption in which the entire production of an abusable drug was discontinued, we can isolate consumer-side substitution responses across drugs. We leverage data from multiple sources including the National Survey on Drug Use and Health (NSDUH) and administrative data from the Drug Enforcement Administration (DEA) to measure OxyContin and pain reliever use and data from the National Vital Statistics System (NVSS) to measure overdose deaths related to natural and synthetic (e.g., fentanyl) opioids and heroin. We study mortality both as an important outcome on its own and as a proxy for opioid and heroin substitution. We ultimately assess the net effects of the reformulation on overall overdose deaths. The impacts of this policy are particularly relevant given that the FDA intends to encourage the development of more abuse-deterrent opioids. ${ }^{6}$

Following the OxyContin reformulation in 2010, abuse of prescription opioid medications and overdose deaths decreased for the first time since 1990 (Warner et al., 2014;

\footnotetext{
${ }^{5}$ Other factors may also differentially influence the decisions behind misusing opioids versus heroin. For example, people may consider opioids "safe" since they are legal drugs, prescribed by physicians.

${ }^{6}$ http://www.fda.gov/NewsEvents/Newsroom/PressAnnouncements/ucm492237.htm (accessed May 21, 2016)
} 
Dart et al., 2015). However, this drop coincided with an unprecedented rise in heroin overdoses (see Figure 1). Heroin-related overdoses more than tripled between 2010 and 2014 (from 1.0 to 3.4 deaths per 100,000), after remaining relatively constant between 1999 and 2010. In 2014 alone, heroin was responsible for over 10,000 deaths. This time series evidence is consistent with the hypothesis that the reformulation led individuals to substitute away from OxyContin to heroin. Indeed, prior studies in the medical literature - which have been limited to before and after evaluations of the reformulation (e.g., Coplan et al., 2013; Larochelle et al., 2015)— have suggested there is a relationship between these recent trends. ${ }^{7}$ However, it is difficult to isolate the effects of OxyContin reformulation from other concurrent changes in state and federal policies that have sought to address the rise in opioid abuse during the same time period.

We address the challenge of identifying the effects of a national intervention separately from other policy and secular trends, by exploiting across state variation in pre-reformulation rates of OxyContin misuse. The reformulation should have more "bite" in states with higher initial rates of OxyContin misuse. Consistent with our hypothesis, we show that states with high initial OxyContin misuse experience larger declines in OxyContin misuse immediately following the reformulation. We exploit this differential exposure to the reformulation across states to quantify its effects on opioid deaths and substitution to other drugs.

We find that the OxyContin reformulation significantly reduced OxyContin misuse, but also led to a large increase in heroin deaths. Specifically, states with the highest initial rates of OxyContin misuse experienced the largest increases in heroin deaths. Event study results show that this differential increase in heroin deaths began precisely in the year following reformulation. Moreover, heroin deaths were uncorrelated with OxyContin misuse prior to the reformulation: both the levels and trends in heroin deaths were nearly identical across states with high or low initial rates of OxyContin misuse before 2010. Our estimates show that each additional percentage point of pre-reformulation OxyContin misuse is associated with a relative decrease in OxyContin misuse of 0.8 percentage points and an additional 2.5 heroin deaths per 100,000 through 2013. These estimates imply that each percentage point reduction in the rate of OxyContin misuse due to reformulation leads to 3.1 more heroin-related deaths per 100,000.

\footnotetext{
${ }^{7}$ Prior medical studies surveying patients in substance abuse treatment programs (e.g., Cicero et al., 2015; Butler et al., 2013) found evidence of a reduction in abuse of OxyContin following reformulation, as well as substitution to other opioids and heroin.
} 
Extrapolating our estimates to the national trend implies that as much as $80 \%$ of the three-fold increase in heroin mortality since 2010 may be due to the OxyContin reformulation.

On the other hand, we find less evidence of differential reductions in overall opioid mortality following the reformulation in states with high initial OxyContin misuse. While we estimate a reduction of 0.8 opioid deaths per 100,000 for each additional percentage point of prereformulation OxyContin misuse, this estimate is not statistically significant. When focusing on natural opioids (e.g., oxycodone and hydrocodone) alone, we find stronger evidence of mortality reductions after the reformulation (2.4 deaths per 100,000) but these estimates are only marginally statistically significant. The lack of significant effects suggests that there has been an increase in substitution from OxyContin to other types of opioids, counteracting the potential mortality gains from the reduction in OxyContin misuse. One particularly concerning substitution pattern is towards more harmful synthetic opioids, such as fentanyl, which have recently gained attention due to a sharp rise in fentanyl-related deaths. ${ }^{8}$ Studying synthetic opioids independently, we find suggestive evidence of a relative increase in deaths in high initial OxyContin misuse states. Finally, we show that the impact of the reformulation on heroin and opioid deaths largely offset each other, leading to no net reduction in overall overdose deaths.

Given the considerable policy efforts to reduce opioid abuse during this time period as well as concurrent supply and demand shocks for opioids and heroin, we conduct several tests to verify that our results represent a causal effect of the reformulation. Focusing on other major policies introduced around 2010, we show that our results are not sensitive to controlling for the differential adoption of PDMPs or excluding Florida - which experienced a significant crackdown on "pill mills" operating in the state in 2010 and 2011. ${ }^{9}$ Furthermore, we exploit the independent variation across states in initial nonmedical OxyContin use from initial nonmedical pain reliever use more generally. We find that nonmedical use of OxyContin, specifically, is predictive of growth in heroin mortality while initial nonmedical use of pain relievers more generally is not. We also show that reductions in heroin prices, as well as changes in economic conditions, are uncorrelated with initial OxyContin misuse. These tests are consistent with reformulation driving the rise in heroin overdoses and not secular trends or other policies which would likely affect misuse of a broader set of pain relievers.

\footnotetext{
${ }^{8}$ http://emergency.cdc.gov/han/han00384.asp (accessed May 29, 2016)

${ }^{9}$ We also exclude other states that were impacted by Florida pill mills.
} 
This study quantifies the high degree of substitutability between heroin and medicallyintended opiates in response to a large supply reduction in abusable OxyContin. While opioid policies have generally focused on disrupting the supply of opioids for nonmedical use, our findings demonstrate how the availability of unregulated substitute drugs can severely undermine the effectiveness of such policies. In principle, it is plausible that heroin is a substitute in the short-term but a complement in the longer-term, suggesting scope for the reformulation to have future benefits. Reducing the supply of abusable opioids may diminish the probability of initiation into opiate abuse and gradually shrink the population that potentially transitions from medically-intended opioids to heroin over time. Although we can only study the first three years after the policy, we find no evidence that the reformulation effect is shrinking over time; in fact, we estimate that the effect on heroin use gets larger in each subsequent year. While the introduction of OxyContin is often blamed for initiating the opioid epidemic, the removal of the original formulation of OxyContin coincided with a dramatic rise in heroin deaths. This study illustrates the challenges of addressing a deep-rooted addiction epidemic using supply side strategies in the presence of substitute drugs.

\section{Background}

In this section, we provide background on the historical importance of OxyContin as an innovation in pain management and how it became one of the most widely abused prescription drugs. We then discuss the abuse-deterrent reformulation of OxyContin and the current state of the literature on understanding its consequences on individual behavior.

\section{Background on OxyContin}

OxyContin was introduced by Purdue Pharma in 1996 and is the brand-name drug for the extended-release formulation of oxycodone. Oxycodone is a semi-synthetic opioid which is classified in the United States as a Schedule II controlled substance, similar to morphine. OxyContin is primarily used for the management of acute or chronic pain, including pain due to injuries, cancer, and other conditions. The key innovation of OxyContin was its long-acting formula which provided 12 hours of continuous pain relief, significantly improving the quality and ease of pain management over previous drugs. However, the timed-release aspect of OxyContin is contingent on taking the pill whole. Crushing or dissolving the pill causes the high 
dose of oxycodone, which is intended to be released slowly over 12 hours, to be delivered all at once. This property made OxyContin especially easy to abuse. Individuals who intended to abuse OxyContin could chew, snort or inject the crushed pill for maximum euphoric effects. This method of abuse is arguably the most dangerous, as this high level of potency comes with a heightened risk for addiction and overdose death. Ironically, it was the time-released aspect of OxyContin that led FDA officials to initially believe that OxyContin would be less attractive to abusers since absorption of the drug would be delayed. As a result, the original product label included the false statement that OxyContin had a lower potential for abuse than other oxycodone products. This claim became a cornerstone of the marketing campaign for the drug (GAO, 2003).

OxyContin sales increased rapidly from $\$ 45$ million in 1996 to more than $\$ 3$ billion in 2010 (GAO, 2003; Bartholow, 2011). It ranked as the $15^{\text {th }}$ highest selling prescription drug in the U.S. in terms of retail sales and the top selling drug in the class of prescription opioid pain relievers (Bartholow, 2011). This growth was partially fueled by an aggressive marketing campaign which promoted the drug for a wide range of conditions, including non-cancer chronic pain, and as a first line therapy (GAO, 2003). This departed from previous clinical recommendations to prescribe opioid pain relievers only after other drugs had failed (WHO Expert Committee, 1986) and primarily for acute and cancer pain (Max et al., 1995). OxyContin prescriptions for non-cancer pain increased nearly tenfold from 1997 to 2002 (fourfold for cancer pain). Non-cancer pain was a relatively untapped market in which the risk of addiction was less well-known (GAO, 2003). Consequently, there was a massive expansion of opioids prescribed by primary care physicians (as opposed to specialty physicians such as oncologists), who had more limited training in pain management. The marketing campaign also inflated claims of the drug's safety. In 2007, Purdue Pharma pleaded guilty to misleading users about the risk of addiction with OxyContin, leading to an over $\$ 600$ million settlement for criminal and civil charges.

The culture surrounding the use of opioids was also changing in the mid-1990s. In 1995, the American Pain Society recommended that pain should be assessed as the "fifth vital sign" (along with blood pressure, temperature, pulse and respiratory rate) and the increasing importance of treating pain led national pain organizations to revise treatment guidelines to recommend the use of opioids in treating both cancer and non-cancer pain (Phillips, 2000). 
The increased market presence of OxyContin during this time period led to high levels of diversion to non-medical use. OxyContin became one of the leading drugs of abuse in the U.S. (Cicero et al., 2005) and it was the first drug targeted for monitoring by the DEA by its brand name, specifically, because of its high frequency of abuse (GAO, 2003). Given that the introduction of OxyContin coincided with the beginning of the opioid epidemic in the mid1990s, it is often cited as a key factor in driving the increasing trend in opioid abuse and deaths (e.g., Kolodny et al., 2015).

\section{The OxyContin Reformulation}

In April 2010, Purdue Pharma introduced a reformulated version of OxyContin which was designed to make the drug more difficult to abuse. It was the first drug product to ever receive an "abuse-deterrent" designation from the FDA. ${ }^{10}$ The abuse-deterrent version uses physicochemical barriers to make the pill hard to break, crush or dissolve, thus deterring the most harmful methods of abuse while still maintaining the pain-relieving benefits for legitimate medical users who take the drug orally. In August 2010, Purdue Pharma stopped distributing the original formulation of OxyContin to pharmacies. It should be noted that the reformulation is not entirely “abuse-proof," since it cannot deter oral misuse (i.e., taking more pills or higher doses than prescribed), and some users have even found ways to counteract the abuse-deterrent properties of the new version. ${ }^{11}$ When the original formulation of OxyContin lost patent protection in April 2013, the FDA announced that they would not approve any generic versions of the original OxyContin formulation, since they determined that the benefits no longer outweighed its risks. Consequently, only the reformulated version has been distributed to pharmacies since August 2010.

There was an immediate reduction in OxyContin misuse and oxycodone distribution at the national level after the reformulation, as shown in Figure 2. We find that self-reported misuse of OxyContin declined by more than 20 percent between the 2010 and 2012 waves of the NSDUH data. Total legal distribution of oxycodone — as recorded by the DEA — also declined for the first time after the reformulation, following a steady increase since 2000. Although it is

\footnotetext{
${ }^{10}$ This reformulated version received an official “abuse-deterrent” designation from the FDA in April 2013.

${ }^{11}$ Highly sophisticated methods were shared on websites for how to counteract the abuse-deterrent properties of the drug. However, given the significant effort required, these methods may prove too costly for most users (Cicero and Ellis, 2015).
} 
possible for patients to switch from OxyContin to other oxycodone drugs after the reformulation, such a pattern does not appear to dominate because the trend in oxycodone use after 2010 is still downwards. Our findings are consistent with several medical studies showing that the reformulation was effective at reducing OxyContin abuse among recreational users by about 40 percent, with an even larger percentage reduction in non-oral abuse (Cicero et al., 2012; Butler et al., 2013; Cicero et al., 2015).

We use the introduction of abuse-deterrent OxyContin (and the discontinuation of the original formulation) as a large national shock to the supply of abusable opioids. Prior studies in the medical literature have examined survey and surveillance data before and after 2010, showing that the reformulation was associated with a time series reduction in calls to poison control centers for abuse or accidental exposure (Coplan et al., 2013), adverse event reports of death (Sessler et al., 2014), drug diversion reports (Severtson et al., 2013) and abuse among recreational users (Butler et al., 2013; Cassidy et al., 2014; Cicero and Ellis 2015). Most of these studies also find evidence of a rise in heroin use and the use of other opioids. In one widely cited study, Cicero and Ellis (2015) surveyed a small sample ( $\mathrm{N}=153)$ of recreational users of OxyContin, finding that 33\% had indicated that they replaced OxyContin with other drugs in response to the abuse-deterrent formulation. $70 \%$ of this group reported that they had switched to heroin.

While these studies support the plausibility of a causal connection between the OxyContin reformulation and the dramatic increase in heroin and other opioid use, the timeseries research designs limit the ability to separate the role of the OxyContin reformulation from other opioid-related policies; and analysis on small, non-random samples may not generalize to explain national trends. Understanding the empirical substitution patterns between opioids and heroin due to market disruptions is critical for the evaluation of these types of policies. The reformulation represents one of the largest disruptions to the nonmedical market for opioids, presenting a rare opportunity to estimate the relationship between opioid-specific supply-side policies and consumer-level responses. We exploit variation in exposure to the reformulation across states based on initial rates of OxyContin misuse and estimate reformulation impacts for the census of deaths in the U.S. Our approach permits us to account for fixed differences across geographic areas with different exposure rates, control for common national shocks, and test for pre-existing differences across areas. 
The FDA recently announced its intent to encourage the development of more opioid formulations with abuse-deterrent properties. ${ }^{12}$ To date, the FDA has approved abuse-deterrent versions for several brand name extended-release opioids (Targiniq, Embeda, Hysingla, MorphaBond, Xtampza, and Troxyca), though OxyContin remains the most important given its large market size. To the extent that recent heroin overdose trends are due to the introduction of reformulated OxyContin, we might expect that these trends could be exacerbated in the near future as the introduction of other abuse-deterrent opioids cause more users to switch from opioids to heroin. Consequently, it is especially important to understand substitution patterns in response to supply-side opioid policies to predict future trends in drug abuse.

\section{Related Literature}

Supply-side interventions, which reduce access to the targeted drug, have largely dominated the set of policies aimed at reducing drug abuse (Pollack and Reuter, 2014). Economic theory predicts that policies which reduce the supply of drugs - through mechanisms such as enforcement (e.g., seizures and arrests), monitoring, interdiction, and regulation of substances and drug precursors — should increase drug prices, lowering demand for the drug (Caulkins and Reuter, 2010; Reuter and Kleiman, 1996). However, substitution effects driven by cross-price elastic supply or demand for drugs may partially undo the benefits of these policies or reduce their long term impact. In general, there are two possible substitution responses by producers and consumers.

First, the increase in price may attract new suppliers to the market (or increased production by existing suppliers), thereby reducing or even eliminating the supply shortfall. ${ }^{13}$ As just one example, in the market for methamphetamine, interventions that targeted the supply of specific drug precursors were found to have only short term effects on prices because producers could substitute away from using the regulated inputs towards unregulated ones (Cunningham and Finlay, 2016; Dobkin et al., 2014). More generally, supply side interventions have rarely succeeded in eliminating an entire supply chain for a drug, leaving behind alternative sources for production and distribution of the drug. Thus, substitution across producers can mute the price effects (and, hence, the responsiveness of utilization) from these types of

\footnotetext{
12 http://www.fda.gov/NewsEvents/Newsroom/PressAnnouncements/ucm492237.htm (accessed May 21, 2016)

13 The reduction in observed use in response to a supply shock should depend on the slope of the demand curve for that specific drug. If demand is inelastic, then total use (and supply) will remain the same.
} 
interventions. The OxyContin reformulation is a unique intervention in this respect since Purdue Pharma is the sole legal producer of this compound and altogether reduced the supply of its abusable drug formulation immediately and permanently across all markets. Thus, the OxyContin reformulation did not have a producer-level substitution response.

Second, there may be consumer-level substitution responses. By increasing the cost of OxyContin abuse (including the cost of access), the reformulation reduced consumption of OxyContin, but may have also led existing users to substitute to heroin or other pharmacologically similar drugs. This response would undermine the effectiveness of the intervention in reducing overall drug abuse. The magnitude of this consumer substitution response will depend on cross-price elasticities of demand as well as the supply of alternative drugs. The economics literature has long recognized the potential importance of substitution patterns across drugs (e.g., Crost and Guerrero, 2012; DiNardo and Lemieux, 2001; Model, 1993). For example, DiNardo and Lemieux (2001) and Crost and Guerrero (2012) exploit variation in alcohol availability due to the minimum legal drinking age, finding evidence of substitution between alcohol and marijuana. In more closely related work, state medical marijuana laws led to substitution from prescription opioids to marijuana (Powell et al., 2015). Other studies find evidence of complementarities across drugs (e.g., Williams et al, 2004; Saffer and Chaloupka, 1999; Pacula 1998).

We add to this literature in several ways. First, we provide the first natural experiment evidence on the empirical substitutability of prescription opioids and heroin and quantify its importance in explaining recent heroin overdose trends. Second, we test how this effect evolves over time, which is important given that the immediate consequences of reformulation may differ from its future effects on abuse. Finally, we are able to isolate the effects of a large-scale supply disruption on consumer-level substitution from producer-level substitution, since the latter response is not possible in this unique context. Studies of other opioid interventions, such as PDMPs, could potentially confound producer- and consumer-side responses. For example, a PDMP may reduce the supply of opioids diverted from the medical side of the market (e.g., pharmacies) in the state. However, the black market could compensate for this supply reduction by funneling in opioids from out-of-state pharmacies with less stringent PDMPs. The policy implications are very different if supply-side interventions are being undermined by supply-side substitution or demand-side substitution. We isolate the consumer-level substitution response. 


\section{Data and Descriptive Statistics}

To estimate the impact of the introduction of abuse-deterrent OxyContin, we combine several data sources to measure: 1) OxyContin and prescription pain reliever use and 2) opioid and heroin-related overdose deaths and overall overdose deaths. In this section we provide details about each of these data sources.

\section{Nonmedical Opioid Use}

To measure nonmedical use of OxyContin and pain relievers, we use aggregated, state-level data from the National Survey on Drug Use and Health (NSDUH). The NSDUH, which is sponsored by SAMHSA, is a nationally representative household survey of individuals ages 12 and older and is the largest annual survey collecting information on substance use and mental health issues in the U.S. The survey provides information on self-reported "nonmedical OxyContin use" as well as "nonmedical pain reliever use" within the past year. The publicly available NSDUH data are available in two year waves. ${ }^{14}$ The NSDUH began asking about nonmedical use for pain relievers in 2002 and for OxyContin in 2004. We use nonmedical OxyContin use rates from the 2004-2005, 2006-2007, 2008-2009, 2010-2011, and 2012-2013 waves, and we will refer to each wave by its first year.

We use the NSDUH data to construct our main measure of OxyContin misuse for two reasons. First, it specifies OxyContin in the survey question, which is the exact drug product affected by the reformulation. Second, it specifies nonmedical use. Nonmedical use or misuse has been defined in a variety of different ways but generally captures use by individuals who either: a) were not the ones originally prescribed the medication or b) use it in a manner inconsistent with what was prescribed by the physician. Alternative data sources on OxyContin use through legal channels, such as pharmacy claims data or reports of legal distribution of oxycodone, may not fully capture the differential effects of the reformulation-which we would expect to affect nonmedical users more than medical users-across states, thus we consider "nonmedical use" as our preferred measure. Our results are robust to using alternative data sources and measures of OxyContin use, which we show in Section 5.3.B. We will also use the

\footnotetext{
${ }^{14}$ It should be noted that SAMHSA recently restricted access to the individual level NSDUH data. Specifically, the portal allowing access to geographically identifiable individual level data in the NSDUH has been closed for over the past year, making it impossible to conduct this work on the NSDUH microlevel data. We use the only NSDUH data currently available to researchers which is aggregated to the state level and available in two year waves. These data are sufficient for the purposes of constructing state-level measures of pre-reformulation OxyContin misuse.
} 
more general measure of nonmedical pain reliever use to disentangle substitution patterns due specifically to OxyContin reformulation from other concurrent policy and secular changes which affected pain reliever misuse more broadly.

Exposure to the reformulation is quantified as state-level pre-reformulation OxyContin misuse. Specifically, we define exposure as the population-weighted rate of OxyContin misuse in each state combining the 2004-2005, 2006-2007, and 2008-2009 waves. We select these years because they precede the 2010 introduction of abuse-deterrent OxyContin and aggregate the waves together to obtain more precise measures of OxyContin misuse rates, reducing concerns about measurement error. We will also present sensitivity analyses where we construct our measure of initial OxyContin misuse using only one wave at a time. The nonmedical pain reliever use variable is constructed similarly. We do not use the NSDUH data to measure statelevel heroin use because heroin (unlike most other drugs) is known to be severely underreported in these data. ${ }^{15}$

We complement these data with information about the legal supply of opioids at the statelevel from the DEA's Automation of Reports and Consolidated Orders System (ARCOS). ${ }^{16}$ The Controlled Substance Act of 1970 requires all manufacturers and distributors to report their transactions and deliveries of all Scheduled II-V substances to the Attorney General. ARCOS is the system that monitors and records the flows of these controlled substances as they move from manufacturers to retail distributors at the state level. Only the active ingredients are reported in this dataset, so we observe the total distribution of oxycodone by state, but not OxyContin specifically. However, OxyContin accounts for a large share of oxycodone distribution. We will use the ARCOS data to show that our measure of pre-reformulation OxyContin misuse is correlated with legal distribution of oxycodone in a state. Also, we will use this data to define alternative measures of exposure to the reformulation based on the relative importance of oxycodone in the state compared to hydrocodone, prior to the reformulation. Hydrocodone (e.g., Vicodin) is another schedule II prescription opioid which is a clinical substitute for oxycodone and is also commonly abused. In a study of opioid-dependent subjects entering drug treatment programs, oxycodone and hydrocodone were the drugs of choice for $75 \%$ of patients (Cicero et

\footnotetext{
${ }^{15}$ https://www.whitehouse.gov/sites/default/files/ondcp/policy-and-research/wausid results report.pdf (accessed May 29, 2016)

${ }^{16}$ This data was obtained through Freedom of Information Act (FOIA) requests to the DEA.
} 
al., 2013). States which disproportionately prescribe oxycodone relative to hydrocodone should also be more affected by the reformulation.

\section{Mortality}

We use the National Vital Statistics System (NVSS) Multiple Cause of Death mortality files - the census of deaths in the U.S. - to study annual overdose deaths from 1999-2013. We use restricted data to access state identifiers. We follow the coding used by the CDC to categorize deaths as opiate-related. First, we code deaths as overdoses by using the ICD-10 external cause of injury codes X40-X44, X60-64, X85, or Y10-Y14. Further, we use drug identification codes, which provide information about the substances found in the body at death. There are four drug identification codes related to opiates. T40.1 indicates poisoning by heroin. Opioid-related deaths (excluding heroin) are identified as: T40.2 for natural and semisynthetic opioids (e.g., oxycodone and hydrocodone), T40.3 for methadone, and T40.4 for synthetic opioids excluding methadone (e.g., fentanyl and tramadol). Following the CDC, we combine T40.2-T40.4 as our measure of total opioid-related deaths. We also study more disaggregated measures of opioid deaths, such as examining T40.2 alone (since the OxyContin reformulation should have the most direct effect on this category) and examining substitution across categories.

\section{Variation in Initial OxyContin Misuse}

As noted above, we measure a state's exposure to the reformulation - initial OxyContin prevalence- as the population-weighted rate of nonmedical OxyContin use pooling NSDUH data from the 2004 through 2008 survey waves. There is significant geographic variation in initial nonmedical OxyContin use, which is illustrated in Figure 3. We exploit this geographic variation in our analysis. There are some clusters of misuse (such as Indiana, Kentucky, and West Virginia), but we see high propensities to misuse throughout different parts of the country. The OxyContin misuse rate ranges from $0.26 \%$ in Illinois to $1.15 \%$ in Rhode Island. Alternative measures of initial OxyContin misuse are correlated with our chosen measure, as shown in Appendix Figure A.1. These figures show that our measure is strongly correlated with the 20042005 misuse rate and, separately, the 2008-2009 misuse rate. Using ARCOS data, we also show that there is a strong correlation between OxyContin misuse and the per capita legal supply of oxycodone. 
Variation in OxyContin misuse could be driven by a number of factors including: variability in the prescribing of specific opioids (not unlike the observed geographic variation in prescribing for other drugs and health care services more generally) due to a lack of consensus on best practices for treating pain patients (Paulozzi et al., 2014); or variability in consumer brand preferences across individuals. For example, OxyContin is more expensive than other opioids, but also delivers a preferred high over hydrocodone. Hydrocodone is often preferred by more risk-averse recreational users such as women and the elderly; while OxyContin is often preferred by more risk-tolerant young men (Cicero et al., 2013).

OxyContin misuse in a state could also be driven by some of the same underlying causes for high rates of pain reliever misuse more generally. To address this, we will also present analyses where we exploit differences in states' total supply of oxycodone relative to hydrocodone to isolate independent variation in OxyContin misuse. As shown in Appendix Table A.1, states with high shares of oxycodone relative to hydrocodone distribution have higher rates of OxyContin misuse but not higher rates of misuse of other types of pain relievers. Conversely, states with a disproportionately high share of hydrocodone relative to oxycodone have higher rates of misuse of other types of pain relievers. Our main analysis will proceed by using OxyContin misuse rates as the measure of exposure because we hypothesize that this is the margin determining substitution to heroin. However, we will also show results using variation in the oxycodone-relative-to-hydrocodone share in order to further isolate changes in outcomes due to the OxyContin reformulation rather than other opioid policies as well as showing that the results are robust to exploiting the underlying legal variation in opioids which generates disparities in nonmedical use.

\section{Descriptive Statistics}

States with higher misuse rates of OxyContin may differ from states with lower misuse rates. Table 1 shows mean outcomes and control variables before the reformulation for states with above and below-median rates of initial OxyContin misuse as measured in the NSDUH. As we would expect, high OxyContin misuse states have more oxycodone doses per capita, more opioid overdoses, and more drug overdoses from all causes. However, the two groups of states have similar heroin mortality rates prior to the OxyContin reformulation. In our analysis below, we will show that these groups also have similar pre-reformulation trends in heroin deaths. The 
age composition is relatively similar across states as are the economic indicators as measured in 2000. However, high OxyContin misuse states have smaller populations and a higher proportion of whites. These differences motivate the inclusion of state fixed effects in our analyses while also testing explicitly for differential trends. Our empirical approach will isolate causal trend breaks due to the OxyContin reformulation from secular trends driven by cross-sectional differences across states.

\section{Empirical Strategy}

We estimate the causal impact of the OxyContin reformulation by exploiting variation in states' exposure to the reformulation due to differences in their initial prevalence of OxyContin misuse. We examine whether states with higher initial rates of OxyContin misuse- which should be more affected by the reformulation - experienced larger changes in heroin and opioidrelated deaths by estimating the following event-study specification:

$$
Y_{s t}=\alpha_{s}+\gamma_{t}+\delta_{t} \times \text { OxyRate }{ }_{s}^{\text {Pre }}+X_{s t}^{\prime} \beta+\varepsilon_{s t},
$$

where $Y_{s t}$ is the number of heroin or opioid deaths per 100,000 in state $s$ and year $t$. OxyRate Pre $^{\text {Pre }}$ is the fixed rate of OxyContin misuse in state $s$ in the pre-reformulation period (measured between the 2004-2008 NSDUH waves) and is interacted with a full set of year fixed effects $\delta_{t} . X_{s t}$ is a vector of state and time-varying covariates including the unemployment rate, fraction of the population ages 18-64, and fraction of the population ages 65+. We control for state fixed effects $\alpha_{s}$ to account for fixed cross-sectional differences across states as well as year fixed effects $\gamma_{t}$ to account for national shocks and trends in heroin availability, enforcement, prices, and other factors common across states. Standard errors are clustered at the state level to account for serial correlation.

The main variables of interest are the full set of $\delta_{t}$ estimates, which we will show graphically, normalizing the 2009 coefficient to equal zero. These estimates identify the differences in mortality across states with higher and lower initial rates of OxyContin misuse in each year and we will test for a trend break after the reformulation in 2010. For example, when the dependent variable is heroin deaths per capita, we expect the estimates of $\delta_{t}$ to increase beginning after 2010 if higher initial OxyContin misuse in the state predicts a larger increase in 
heroin deaths after the OxyContin reformulation. The identifying assumption is that in the absence of the reformulation, differences across states would have continued along the same trends.

We also parameterize the above model to estimate the average effect of the reformulation. Specifically, we estimate a trend-break specification limiting the analysis sample to the years 2008-2013. We focus on the time period close to the reformulation to estimate the linear trend more precisely, although the results are similar if we use a longer pre-period. Our specification is as follows:

$$
\begin{aligned}
Y_{s t}= & \alpha_{s}+\gamma_{t}+\delta_{1}\left[\text { Post }_{t} \times \text { Oxy } \text { Rate }_{s}^{\text {Pre }}\right]+\delta_{2}\left[t \times \text { OxyRate }_{s}^{\text {Pre }}\right] \\
& +\delta_{3}\left[\text { Post }_{t} \times(t-2010) \times \text { OxyRate }_{s}^{\text {Pre }}\right]+X_{s t}^{\prime} \beta+\varepsilon_{s t}
\end{aligned}
$$

where Post $t_{t}$ is an indicator that turns on in 2011 and later and $t$ is a linear time trend-i.e., ( $t-2010$ ) equals 1 in 2011, 2 in 2012, and so forth. This specification controls for pre-existing trends while allowing for both a level shift and trend break in 2011. We restrict the trend break to occur in 2011 based on our results from the non-parametric specification in equation (1). Also, since the discontinuation of the original formulation occurred late in 2010, we expect that patients still had some access to this formulation as pharmacies drew down their inventories. ${ }^{17}$ To the extent that a partial effect occurred in 2010, our estimates should be biased towards zero. In Section 5, we test the sensitivity of the results to the inclusion of 2010 in the analysis sample. Equation (2) is a less flexible version of equation (1) but provides easier to interpret magnitudes for the relationship between initial nonmedical OxyContin use and changes in mortality. After estimating the parameters in equation (2), we report the effects of the OxyContin reformulation through $2013\left(\delta_{1}+3 \delta_{3}\right)$, our last year of data.

We will show that our results are robust to alternative specifications-such as controlling for state-specific trends - and we also test for alternative explanations for the patterns in opioid and heroin mortality. Specifically, we control for the differential adoption of PDMPs across states and, in some specifications, we also exclude states such as Florida, West Virginia, and Kentucky that were affected by changes in pain clinic laws occurring around the time of the reformulation. We also test for differential changes in heroin prices and economic conditions.

\footnotetext{
${ }^{17}$ Prescriptions filled at pharmacies for the original formulation of OxyContin accounted for 7.4\%, 1.8\%, and 0.6\% of total OxyContin prescriptions in January 2011, June 2011, and December 2011, respectively (Butler, et al. 2013).
} 
Finally, we provide estimates where we control for initial nonmedical pain reliever use in addition to initial OxyContin misuse. Including both variables allows us to isolate the effect of the OxyContin reformulation relative to other policies, such as PDMPs, which affect opioid abuse more broadly. If OxyContin reformulation is the driving force behind the change in opioid and heroin mortality rates, then we would expect that the changes in these outcomes would load on the OxyContin misuse variable rather than on the more encompassing nonmedical pain reliever use variable.

\section{Results}

Our analysis proceeds in three steps. First, we provide evidence for our key underlying assumption that OxyContin misuse declined more after the reformulation in states with higher initial OxyContin misuse. Second, we estimate the causal impact of this reduction in OxyContin misuse due to reformulation on overall opioid abuse and substitution to other opiates. We estimate mortality effects and separately identify deaths caused by different types of opioids and heroin as well as the impact on overall overdose deaths. Third, we investigate alternative channels for the observed substitution patterns across drugs, including other state-level opioid policies, changes in heroin prices, and economic shocks.

\subsection{First Stage Effects of Reformulation on OxyContin Use}

We begin by showing graphically that the initial rate of OxyContin misuse in a state is strongly predictive of differential changes in OxyContin misuse after the 2010 reformulation. This is a necessary condition for using variation in initial OxyContin misuse to identify the reformulation's impact. Figure 4 shows the “first stage" relationship between the prereformulation OxyContin misuse rate and the change in the OxyContin misuse rate between the 2008 and 2012 waves in the NSDUH data. We divide states into quartiles based on their initial OxyContin misuse and plot the histogram of rate changes. As predicted, we observe a monotonic relationship between initial OxyContin misuse and reductions in misuse after the reformulation. In states with the highest initial OxyContin misuse, the rate of OxyContin misuse declined by more than 50 percentage points after the reformulation, while OxyContin misuse actually increased slightly in states with the lowest rates of initial OxyContin misuse. 
Figure 5 shows an analogous event study using the continuous measure of initial OxyContin misuse instead of quartiles, estimating a specification analogous to equation (1). NSDUH provides data for two-year waves so we should expect to observe a partial effect for the 2010-2011 estimate followed by a full effect for 2012-2013. We observe a relative decrease in 2010-2011 for states with higher initial misuse rates followed by an even larger decrease in 2012-2013, as expected. The 2012-2013 estimate indicates that each percentage point increase in initial nonmedical OxyContin use is associated with a decrease in misuse of 0.8 percentage points after reformulation.

\subsection{Effects of OxyContin Reformulation on Mortality}

The previous results establish that states with high initial rates of OxyContin misuse experienced a larger decrease in OxyContin misuse after the introduction of abuse-deterrent OxyContin relative to states with low initial rates. Next, we examine whether there are corresponding changes in mortality as a result of this differential decrease in OxyContin misuse.

\section{Graphical Event Study Results}

Figure 6 presents the full set of coefficients from estimating our baseline event-study specification (equation 1) for several mortality outcomes. The first graph in Panel A shows the point estimates and 95\% confidence intervals for total opioid-related mortality. There is an upward trend in opioid overdose deaths as a function of initial OxyContin misuse before the reformulation. This shows, not surprisingly, that opioid deaths per capita were growing faster in states with high initial OxyContin misuse. Following the 2010 reformulation, we observe some evidence of a leveling off and a small relative decline in opioid deaths in states with higher initial OxyContin misuse. However, while the point estimates decline, the confidence intervals widen in 2010, making it difficult to reject that the reformulation had no effect on opioid mortality. It should be noted that this figure includes all opioid overdoses, not just those specifically involving OxyContin, adding noise to our overdose measure. The outcome variable also encompasses substitution to other types of opioids. In the analysis below, we will examine disaggregated measures of opioid deaths to study the importance of substitution.

The results for heroin overdose deaths are even more stark (second graph in Panel A). The event study coefficients are close to zero and statistically insignificant in every year before 
the reformulation. This indicates that there were no differences in pre-reformulation trends in heroin deaths per capita across states with high and low initial rates of OxyContin misuse. Moreover, as shown in Table 1, there was almost no difference in the levels of per capita heroin deaths across these states. In fact, the correlation between our OxyContin misuse measure and per-capita heroin deaths before 2010 is only 0.015. However, following the reformulation in 2010, there is a sudden statistically significant relative increase in heroin deaths in states with the highest initial rates of OxyContin misuse. The magnitude of this differential effect grows larger in 2012 and again in 2013. The timing of this effect, which coincides precisely with the reformulation, and the fact that this effect is concentrated among states with the highest initial OxyContin use strongly suggests a causal relationship between the OxyContin reformulation and the sharp increase in heroin deaths. We further explore the causality of this relationship in the sections below.

In Panel B, we show the net effects of the reformulation on all drug overdose deaths. For opioid and heroin deaths combined, there is an increasing trend in the coefficients before the reformulation which flattens slightly in 2012. We observe a similar trend for all drug overdoses, which includes non-opiate drugs (e.g., cocaine). However, the confidence intervals also widen in 2011 which make it difficult to statistically reject that there is no effect, as we will discuss further below. This suggests that substitution to heroin (and the corresponding increase in deaths) largely offsets the effects of the reformulation on opioid deaths.

\section{Regression Results}

In this section, we present the parameterized estimates from equation (2) to quantify the total magnitude of the impacts of the OxyContin reformulation. In all tables, we report the "three-year effect" of the reformulation (i.e., the effect through 2013), combining the intercept and slope shift coefficients from equation (2). Specifically, we report estimates of $\delta_{1}+3 \delta_{3}$.

\section{A. Heroin Mortality}

The results for heroin deaths from the parameterized model are presented in Table 2. In Column (1), we report an effect of 2.2, implying that a 1 percentage point higher rate of initial OxyContin misuse leads to an additional 2.2 heroin deaths per 100,000 through 2013, which is statistically significant at the 5\% level. This estimate indicates that each standard deviation 
increase in the initial OxyContin misuse rate is associated with an additional 0.50 heroin deaths per 100,000 in 2013, a 47\% increase relative to the baseline mean of 1.06 .

In Column (2) of Table 2, we include time-varying state-level covariates. The estimate increases in magnitude to 2.5 and remains statistically different from zero. Column (3) presents the results when both initial OxyContin misuse and initial pain reliever use ${ }^{18}$ are included. This test is important because the two variables are correlated and our initial OxyContin measure is potentially picking up some effects related to initial pain reliever misuse more generally. The Column (3) estimates, however, suggest that not accounting for pain reliever misuse is actually biasing the estimates downward. In this specification, we estimate that an additional percentage point of nonmedical OxyContin use before reformulation increases heroin deaths by 3.7 deaths per 100,000 in 2013. ${ }^{19}$

In the final two columns of Table 2, we test the sensitivity of the results to functional form by implementing Poisson regressions (the corresponding event studies are shown in Appendix Figure A.2). Since states have different initial mortality rates, it may be useful to model the effect of reformulation as having a proportional effect from these different baselines. For heroin deaths, these baseline differences are not systematically related to initial nonmedical OxyContin use so we do not expect that the use of a linear specification is driving our conclusions, though they may be important for opioid deaths. Poisson regression permits the estimation of proportional effects and has several advantages over estimating a linear specification with a logarithmic outcome variable (see Santos Silva and Tenreyro, 2006), especially when the outcome includes zeros (which occurs for about $12 \%$ of state-years in the full sample and 6\% in the 2008-2013 sample). ${ }^{20}$ These estimates are reported in percentage terms so they cannot be directly compared to the other coefficients. In Column (4), we estimate that a 1 percentage point higher initial OxyContin misuse rate increases heroin deaths by 125\% (p-value=0.105). This estimate implies that a standard deviation increase in the initial OxyContin misuse rate would lead to a $41 \%$ increase in deaths relative to the baseline mean,

\footnotetext{
${ }^{18}$ This measure is constructed similarly to initial OxyContin misuse and is included in equation (2) on its own by interacting the initial rate with a post-2010 indicator, a linear time trend, and a post-2010 time trend.

${ }^{19}$ This estimate implies that each standard deviation increase in the initial nonmedical OxyContin misuse rate increased heroin deaths per 100,000 people in 2013 by 0.78 .

${ }^{20}$ While it is commonly believed that Poisson regression requires that the mean equals the variance, this restriction is not enforced to generate the estimates from Poisson regression. Similar estimators, such as negative binomial regression, will impose related restrictions. Poisson regression, therefore, is often considered "more robust" than these alternative estimators. See Wooldridge (2002), Chapter 19 for more details.
} 
similar to the estimates from the linear specification estimated above. In Column (5), we include both pre-reformulation misuse measures. The estimated relationship between initial OxyContin misuse and heroin deaths increases and is statistically significant at the $5 \%$ level.

\section{B. Opioid Mortality}

Table 3 presents the analogous estimates for opioid-related mortality. In Panel A, we estimate the effects of the reformulation for total opioid deaths per 100,000 (drug codes T40.2T40.4). The point estimates suggest that the reformulation differentially decreased overall opioid deaths in areas with high initial OxyContin misuse, but the estimates are too noisy to statistically reject that there is no effect. In Column (1), we find that each percentage point of nonmedical OxyContin use in the pre-period is associated with a decrease of 1.1 opioid deaths per 100,000 after reformulation, but this relationship is not statistically significant. Consistent with this, in the corresponding event study shown in Figure 6, we observed a flattening trend around the time of reformulation, though the confidence intervals were wide. Adding covariates in Column (2) decreases the magnitude of the estimate to 0.8 . When we jointly estimate the effects of initial OxyContin and pain reliever misuse in Column (3), we find that high OxyContin misuse is associated with a statistically insignificant increase in opioid-related deaths after reformulation. Initial pain reliever use leads to a decrease in opioid-related mortality, though neither effect is statistically significant. The Poisson estimates in Columns (4) and (5) also find no statistical relationship between initial OxyContin misuse and changes in opioid-related mortality. In fact, the point estimates are positive. For heroin mortality, there was almost no correlation between initial OxyContin misuse and the death rate. This is not the case for opioid deaths which is one reason that the OLS and Poisson estimates are different.

Panel A represents the broadest definition of opioids, possibly explaining these null results, at least in part. The analysis aggregates together all types of opioids (T40.2-T40.4), though we might expect the reformulation to have a negative effect on deaths due to oxycodone (T40.2) and a positive effect on deaths due to synthetic opioids (T40.4) due to substitution effects. This may cause offsetting effects which mask changes in opioid deaths for specific types of opioids. We explore this heterogeneity below.

\section{Opioid Mortality due to Natural Opioids}


In Panel B, we present estimates for deaths from natural opioids (T40.2), which includes drugs such as oxycodone and hydrocodone (the corresponding event study is in Appendix Figure A.3). For natural opioids, the point estimates more than double, but we still cannot statistically reject that there is no effect. Since the class of natural opioids includes more than just OxyContin, we may still be capturing some amount of substitution within the class.

Parsing the data further, in Panel C, we consider the effects of the reformulation on natural opioid-only mortality, excluding overdose deaths with multiple substances (the event study is presented in Appendix Figure A.3). Specifically, we construct deaths due to natural opioids excluding deaths that also involve methadone (T40.3) or synthetic opioids (T40.4). In this specification, the effects become marginally statistically significant at the $10 \%$ level. The pattern across Panels A through C shows that as we more precisely isolate deaths involving OxyContin, we find greater evidence of a differential reduction in deaths following the reformulation. However, there are limits to this exercise and, overall, the evidence of reductions in natural opioid deaths due to the reformulation is only suggestive.

\section{Opioid Mortality due to Synthetic Opioids}

While we find strong evidence of substitution to heroin after reformulation, we also hypothesize that the reformulation may have caused substitution to other types of opioids. If this occurred, it may explain part of the recent rise in deaths due to fentanyl and other synthetic opioids which are more dangerous than oxycodone. Deaths associated with these drugs are categorized as T40.4.

Table 4 presents the estimates for synthetic opioid deaths (the corresponding event study is in Appendix Figure A.3). In Columns (1) and (2) of Panel A, the effect of the reformulation is positive, but not statistically significant. However, when we also control for initial pain reliever use in Column (3), we estimate a statistically significant positive effect at the $5 \%$ level, suggesting that each additional percentage point of initial OxyContin misuse led to an additional 0.8 synthetic opioid deaths per 100,000. Scaled differently, a standard deviation increase in initial OxyContin misuse predicts an additional 0.2 synthetic opioids deaths per 100,000 in 2013. When we estimate proportional effects using Poisson regression, we find much larger effects for synthetic opioid deaths. Given that there are large cross-sectional differences in synthetic opioid mortality correlated with initial OxyContin misuse before the reformulation, estimating 
proportional effects is more appropriate and explains the more precise estimates when using Poisson regression. In Column (4), we estimate that a one standard deviation higher initial OxyContin misuse rate leads to an additional $28 \%$ increase in synthetic opioid mortality after reformulation. When we jointly estimate the effects of initial OxyContin and initial pain reliever use, this OxyContin estimate increases to 34\%. The graphical event study using Poisson regression presents complementary evidence (see Appendix Figure A.2) that the postreformulation estimates are more precise than the OLS event study and imply statistically significant increases with little evidence of differential pre-existing trends. In Panel B of Table 4, we estimate the effects for deaths due to synthetic opioids while excluding deaths that also involve methadone or natural opioids. The estimates are similar. Taken together, this evidence is suggestive that the reformulation of OxyContin may have increased deaths involving synthetic opioids such as fentanyl.

\section{E. Total Overdose Deaths}

In Table 5, we explore the effect of reformulation on total overdose deaths. We have previously shown evidence that reformulation increased heroin mortality, but we also find negative (though mostly insignificant) effects on opioid-related deaths. The overall effect is of special interest to understand the net impact of reformulation on drug abuse.

In Panel A, we first replicate our previous tables, but using opioid and heroin deaths combined per 100,000 as the outcome. We estimate positive effects of the reformulation on deaths from opioids and heroin across all models, though these estimates are never statistically distinguishable from zero. We also examine total overdose deaths, including non-opiate drugs (see Panel B). We find that initial nonmedical OxyContin use is not statistically significantly related to changes in drug overdoses overall, regardless of specification or estimation technique. The estimates are positive, though small, which is consistent with the heroin and synthetic opioid effects dominating. However, for both outcome variables in Table 5, there is too much noise to estimate the effects precisely. Overall, the results suggest that the increase in deaths from heroin and fentanyl offset any reductions in natural opioid deaths. 


\subsection{Robustness Tests}

\section{A. Alternative Specifications}

In this section, we explore the robustness of our findings. We focus our discussion on heroin deaths, but find that the results for opioids deaths are also robust to alternative specifications. These robustness tests are presented in Appendix Table A.2. Panel A shows the tests for heroin deaths and Panel B for opioid-related deaths.

In Column (1), we present our preferred estimate for heroin deaths (from Table 2, Column 2) of 2.54 to compare to the results from our alternative specifications. In Column (2), we exclude 2010 from the analysis, since this is a partially treated year. We estimate a slightly larger effect of 2.86. In Column (3), we test for the importance of weighting by state population (Solon et al., 2014). When we do not use population weights, we estimate a statistically significant effect of 3.67. In Column (4), we include state-specific trends. Accounting for statespecific trends is difficult in this context because the treatment effect is not constant over time (as seen in the event studies) and there may be heterogeneity across states as well. Wolfers (2006) suggests that state-specific trends may attenuate the estimates given such heterogeneous effects. Our estimate does decrease as expected, but we still estimate a statistically significant effect of 1.88. In Column (5), we present estimates using the full sample period (1999-2013). We had used 2008-2013 in our primary analyses to restrict to the years around reformulation and avoid fitting the pre-existing linear trend on data from over a decade before the intervention. When we use the full sample, we estimate an effect of 2.10, which is similar to our main estimate.

In Column (6), we replace our initial OxyContin misuse measure, constructed using the 2004-2008 NSDUH waves, with a similar measure constructed using the 2004-2005 wave only. The advantage of using this wave is that it pre-dates the 2008-2013 analysis sample. States which experience a transitory shock to opioid abuse might experience different changes in heroin abuse over time due to mean reversion, even in the absence of the reformulation. Using data further from the time of treatment reduces concerns that mean reversion is driving our estimates. On the other hand, the disadvantage of using only one year of data is that it exacerbates measurement error concerns. Using the 2004-2005 measure, we estimate an effect of 2.41, similar to our main estimate. In Column (7), we show the corresponding estimate using the 2008-2009 wave - the year before reformulation — to construct our initial OxyContin misuse 
measure and estimate an effect of 1.35, still statistically significant from zero. The decrease in magnitude results partially from the noisiness of the measure constructed from one wave.

In general, measurement error in our measure of OxyContin misuse should attenuate our estimates. To explore this further, in a separate analysis, we replicate the Column (7) estimates in an instrumental variables framework to address measurement error concerns. We use the rates of initial OxyContin misuse from one wave to instrument the rates from a separate wave. ${ }^{21}$ This analysis, shown in Appendix Table A.3, provides further evidence that the single wave results contain measurement error, motivating the aggregation of waves in our main analysis.

Finally, it may be important to account for differences in age composition across states and time when studying overdose rates, beyond the age composition control variables we include in the regression model. Our summary statistics suggest that a state's age distribution is not predictive of OxyContin misuse, but we verify that age composition differences are not driving our results by age-adjusting our mortality rates. In Column (8), we use an age-adjusted heroin overdose rate. $^{22}$ We estimate a similar effect as our main result when we use the age-adjusted measure.

\section{B. Alternative Measures of Exposure to the Reformulation}

Our empirical strategy studies the differential effect of the OxyContin reformulation across states with the idea that states with a high initial rate of OxyContin misuse should be most affected by the reformulation. In this section, we show that our results are robust to alternative measures of exposure to the reformulation. We present these results as graphical event studies in Figure 7.

First, in Panel A, we define a state's exposure to the reformulation as the initial rate of OxyContin misuse divided by the initial rate of pain reliever misuse. This variable captures the fraction of individuals misusing pain relievers who are misusing OxyContin specifically. Thus, it accounts for differences in the rate of overall pain reliever misuse across states. Second, in

\footnotetext{
${ }^{21}$ We replicate the Appendix Table A.2, Column (7) model but estimate it using 2SLS with the 2004-2005 misuse measure to generate the excluded instruments. The 2SLS estimate (see Column 1 of Table A3) implies that each percentage point increase in nonmedical OxyContin misuse in 2008-2009 leads to an additional 4.3 heroin-related deaths per 100,000 people. The estimate is larger than the size of the OLS estimate, which is suggestive that the year-by-year measures have measurement error. The corresponding event study is included in Appendix Figure A.4.

${ }^{22}$ We construct age-specific mortality rates and then take a weighted average, where the weights are calculated using the national 2008 age distribution and are held constant across all observations.
} 
Panel B, we use ARCOS data to define a state's exposure as the initial supply of oxycodone (in morphine equivalent doses) divided by the total initial supply of oxycodone and hydrocodone combined. While oxycodone and hydrocodone are generally considered to be substitutes, there is state variation in the relative size of the supplies of these drugs. We previously discussed some of the possible underlying mechanisms driving the cross-state variation in oxycodone vs. hydrocodone supply in Section 3 (as previously shown in Appendix Table A.1). Finally, Panel C replicates Panel B but uses the ratio of initial oxycodone supply to initial hydrocodone supply.

Using all three measures, the event study pattern is very similar to our previous event study results using the OxyContin misuse measure alone. Overall, we find that our results are not sensitive to how we construct our measure of exposure to the reformulation. Moreover, these alternative measures suggest that our results are due to policies targeting OxyContin/oxycodone use specifically, and not due to policies for opioid abuse overall.

\section{Alternative Explanations}

In Table 6, we consider an array of alternative explanations for the relationship between initial OxyContin misuse rates and changes in heroin deaths. First, we repeat our main estimate of 2.54 in Column (1). Next, in Column (2) we include a time-varying indicator variable for whether the state has a PDMP. Including this variable in the model causes the estimate to increase to 2.89. Evidence on the effectiveness of PDMPs is mixed, with a recent study suggesting that "must access” PDMPs reduce opioid abuse while PDMPs without such provisions have limited effects (Buchmueller and Carey, 2016). In Column (3), we control for whether a state had a "must access” PDMP and find similar effects.

Another concern is whether pill mill laws enacted in Florida around the time of the reformulation may explain part of the observed heroin effect. Florida experienced a dramatic rise in opioid supply in the 2000s due to lax regulations permitting the spread of "pill mills" throughout the state. In response, a complementary package of laws was passed in 2010 and 2011 which increased the regulation of pill mills and shut down many of these pain clinics (see Surrat et al., 2014 and Johnson et al., 2014 for more details). Given that the timing of this crackdown coincided with the reformulation of OxyContin, we address whether the rise in heroin mortality is primarily due to Florida policies. In Column (4) we exclude Florida from the sample, finding an estimate that is very close to our main estimate, increasing slightly to 2.56 . 
The Florida pill mills prescribed and sold opioids to out-of-state residents as well. There is some evidence that a large share of these opioids were sold to residents of Kentucky ${ }^{23}$ and West Virginia. When we exclude Florida, Kentucky, and West Virginia, the estimate decreases to 2.06 but remains statistically significant from zero at the $5 \%$ level. More generally, the pill mills primarily affected the eastern portion of the United States and there is little evidence of noteworthy diversion to the western region. In Column (5), we include only the West Census Region and estimate a coefficient of 3.11, which is even larger than our main estimate.

Appendix Table A.4 replicates Table 6 for opioid-related mortality. As before, there is little evidence of any effect for opioid overdose deaths. Overall, the estimated relationship between initial nonmedical OxyContin misuse rates and growth in heroin deaths does not appear to be driven by other policies such as PDMPs and changes in pain clinic laws.

We also estimate our event study specification for heroin prices using the DEA's System to Retrieve Information from Drug Evidence (STRIDE) database which includes information from drug seizures, such as the type of drug, the purity, and the price. We construct state-level measures of heroin prices for 2000-2012. Heroin prices dropped nationally during our time period, continuing the long term downward trend observed over the past two decades (Kilmer et al., 2014). Our time fixed effects account for these national price changes. However, a reduction in heroin prices could explain the rise in heroin abuse if the price change was differential across areas with higher initial rates of OxyContin misuse. In Panel A of Figure 8, we present event study estimates (analogous to equation 1) to examine whether state-level heroin price changes are correlated with initial OxyContin misuse. We find little evidence of any relationship. ${ }^{24}$

Similarly, differential economic shocks across states may also have an independent influence on OxyContin misuse. In Panel B, we repeat the above exercise using the log of the unemployment rate as the outcome variable. We do not observe any evidence that the unemployment rate changed systematically over time in a manner that correlates with our measure of OxyContin misuse.

\section{Placebo Tests}

\footnotetext{
23 http://www.nytimes.com/2011/09/01/us/01drugs.html? r=1 (last accessed October 3, 2016)

${ }^{24}$ While we might expect to observe a price response due to the demand shock, the absence of a relationship is reassuring that other confounding shocks are not affecting our analysis.
} 
We also conduct placebo tests estimating our event study specification for cocaine overdose deaths and, separately, for all drug overdoses excluding heroin and opioids. These estimates are presented in Appendix Figure A5. We find little evidence of effects for other drugs. Other drugs may be complements or substitutes for opioids so it is not clear whether we would expect to observe any relationship, but the statistical absence of any effect is reassuring that the heroin effect is not driven by concurrent demand shocks for drugs more generally that are correlated with our measure of initial OxyContin misuse.

\subsection{Counterfactual Growth in Heroin Deaths}

Finally, we quantify the effect of the reformulation in explaining the dramatic increasing national trend in heroin deaths after 2010. We use the event study estimates shown in Figure 6 to predict per capita heroin deaths. To make this counterfactual prediction, we set the initial OxyContin misuse rate to zero and calculate the heroin death rate in each year. We estimate that reformulation can explain 0.37 heroin deaths per 100,000 in 2011, 0.94 deaths in 2012, and 1.10 deaths in 2013. Between 2010 and 2013, the actual heroin death rate increased by 101\%. We predict that in the absence of reformulation, we would have observed only a $21 \%$ increase. Thus, our estimates imply that OxyContin reformulation is responsible for as much as $80 \%$ of the recent growth in heroin deaths.

\section{Conclusion}

The reformulation of OxyContin represents one of the largest disruptions to date to the supply of abusable opioids. However, the benefits of any market disruption may unravel as producers and consumers respond to the supply shock by substituting to different suppliers (producers) or to other drugs (consumers). In this paper, we isolate the effects of consumer-level substitution responses to quantify the scope for supply-side interventions to reduce overall drug abuse and overdoses when close substitutes are available.

While the prior literature has relied on time series evidence to estimate the effects of the reformulation, we examine differential effects across states based on their pre-reformulation prevalence of OxyContin misuse. We estimate that initial OxyContin misuse rates are predictive of large and statistically significant increases in heroin mortality. This increase begins precisely in the year following the reformulation. Moreover, more general nonmedical pain reliever use 
does not predict an increase in heroin mortality - the increase loads entirely on OxyContin misuse specifically. Each additional percentage point of initial OxyContin misuse is associated with a decrease in OxyContin misuse of 0.8 percentage points and 2.5 additional heroin deaths per 100,000 (using our Table 2, Column 2 estimate). The implied instrumental variable (IV) estimate is that each percentage point reduction of OxyContin misuse due to reformulation increases heroin mortality by 3.1 deaths per 100,000. Overall, we find no evidence that reformulation affected overdose rates overall (across all drugs), suggesting that consumer-side substitution completely unraveled the benefits of the reformulation, at least in the three years following reformulation. We also find suggestive evidence that consumers substituted to synthetic opioids such as fentanyl.

The findings from this study provide yet another example of how supply-side strategies alone are inadequate for dealing with the drug problem, particularly when substitute drugs exist. This is evident in the large substitution towards heroin (and towards other opioids) following the reformulation. As summed up by Cicero and Ellis (2015), “as long as there is a demand for a drug, that demand will be met in some way." Treating underlying demand may prove to be the more effective strategy for dealing with the current opioid epidemic, particularly because substitutes are readily available.

It is also important to recognize that opioid policies, such as the OxyContin reformulation, will have different effects in the short and long run since the composition of new and existing users will change over time. While the reformulation may lead to substitution across drugs for existing users (mitigating the effectiveness in the short run), the policy to reformulate the product may achieve long run effectiveness by deterring new abuse. This may be particularly relevant for other countries whose opioid problems are now just emerging (Karanges et al., 2016; van Amsterdam and van den Brink, 2015); supply-side policies, such as the reformulation, may have higher effectiveness in these cases. Our study can only examine the effects in the first three years, but we find sizable effects in the short-term and these effects only grow over our time period. 


\section{References}

American Pain Society. "Guideline for the use of chronic opioid therapy in chronic noncancer pain: evidence review.” American Academy of Pain Medicine Opioids Guidelines Panel (2009). Chicago, IL.

Bartholow, M. “Top 200 Drugs of 2010.” Pharmacy Times. May 16, 2011.

Buchmueller, Thomas and Colleen Carey. "The Effect of Prescription Drug Monitoring Programs on Opioid Utilization in Medicare." Mimeo (2016).

Butler, Stephen F., Theresa A. Cassidy, Howard Chilcoat, Ryan A. Black, Craig Landau, Simon H. Budman, and Paul M. Coplan. "Abuse rates and routes of administration of reformulated extended-release oxycodone: initial findings from a sentinel surveillance sample of individuals assessed for substance abuse treatment." The Journal of Pain 14, no. 4 (2013): 351-358.

Cassidy, Theresa A., Pronabesh DasMahapatra, Ryan A. Black, Matthew S. Wieman, and Stephen F. Butler. "Changes in prevalence of prescription opioid abuse after introduction of an abuse-deterrent opioid formulation." Pain Medicine 15, no. 3 (2014): 440-451.

Caulkins, Jonathan P., and Peter Reuter. "How drug enforcement affects drug prices." Crime and Justice 39, no. 1 (2010): 213-271.

Centers for Disease Control and Prevention. "Number and age-adjusted rates of drug-poisoning deaths involving opioid analgesics and heroin: United States, 2000-2014.” National Vital Statistics System, Mortality (2016) Available

at: http://www.cdc.gov/nchs/data/health_policy/AADR_drug_poisoning_involving_OA_Heroin _US_2000-2014.pdf

Cicero, Theodore J., and Matthew S. Ellis. "Abuse-deterrent formulations and the prescription opioid abuse epidemic in the United States: lessons learned from OxyContin." JAMA Psychiatry 72, no. 5 (2015): 424-430.

Cicero TJ, Ellis MS, Surratt HL. "Effect of abuse-deterrent formulation of OxyContin.” New England Journal of Medicine; 367, no. 2 (2012): 187-189.

Cicero, Theodore J., Matthew S. Ellis, Hilary L. Surratt, and Steven P. Kurtz. "Factors influencing the selection of hydrocodone and oxycodone as primary opioids in substance abusers seeking treatment in the United States." PAIN 154, no. 12 (2013): 2639-2648.

Cicero T, Inciardi J, Muñoz A. "Trends in abuse of Oxycontin and other opioid analgesics in the United States: 2002-2004.” Journal of Pain. (2005); 6(10):662-72.

Coplan, Paul M., Hrishikesh Kale, Lauren Sandstrom, Craig Landau, and Howard D. Chilcoat. "Changes in oxycodone and heroin exposures in the National Poison Data System after introduction of extended-release oxycodone with abuse-deterrent characteristics." Pharmacoepidemiology and Drug Safety 22, no. 12 (2013): 1274-1282. 
Crost, Benjamin, and Santiago Guerrero. "The effect of alcohol availability on marijuana use: evidence from the minimum legal drinking age." Journal of Health Economics 31, no. 1 (2012): 112-121.

Cunningham, Scott, and Keith Finlay. "Identifying demand responses to illegal drug supply interdictions." Health Economics (2015).

Dart, Richard C., Hilary L. Surratt, Theodore J. Cicero, Mark W. Parrino, S. Geoff Severtson, Becki Bucher-Bartelson, and Jody L. Green. "Trends in opioid analgesic abuse and mortality in the United States." New England Journal of Medicine 372, no. 3 (2015): 241-248.

DiNardo, John, and Thomas Lemieux. "Alcohol, marijuana, and American youth: the unintended consequences of government regulation." Journal of Health Economics 20, no. 6 (2001): 9911010.

Dobkin, Carlos, Nicosia, Nancy, and Weinberg, Matthew. “Are supply-side drug control efforts effective? Evaluating OTC regulations targeting methamphetamine precursors. ” Journal of Public Economics, 120 (2014): 48-61.

Dobkin, Carlos, and Nancy Nicosia. "The war on drugs: methamphetamine, public health, and crime." The American Economic Review 99, no. 1 (2009): 324-349.

Florence, Curtis S., Chao Zhou, Feijun Luo, and Likang Xu. "The economic burden of prescription opioid overdose, abuse, and dependence in the United States, 2013." Medical Care 54, no. 10 (2016): 901-906.

International Narcotics Control Board. "Report of the International Narcotics Control Board for 2008.” (2008): Available at https://www.incb.org/incb/en/publications/annual-reports/annualreport-2008.html

Johnson, Hal, Leonard Paulozzi, Christina Porucznik, Karin Mack, and Blake Herter. "Decline in drug overdose deaths after state policy changes-Florida, 2010-2012." MMWR Morb Mortal Wkly Rep 63, no. 26 (2014): 569-574.

Karanges, E.A., Blanch, B., Buckley, N.A. and Pearson, S.A.. Twenty-five years of prescription opioid use in Australia: a whole-of-population analysis using pharmaceutical claims. British Journal of Clinical Pharmacology (2016).

Kilmer, Beau, Susan Everingham, Jonathan P. Caulkins, Greg Midgette, P. Reuter, R. L. Pacula, R. Burns, B. Han, and R. Lundberg. "What America’s users spend on illicit drugs: 2000-2010." Office of National Drug Control Policy (2014).

Kolodny, A., Courtwright, D., Hwang, C., Kreiner, P., Eadie, J., Clark, T., and G.C. Alexander. "The Prescription Opioid and Heroin Crisis: A Public Health Approach to an Epidemic of Addiction." Annual Review of Public Health. 36 (2015):559-74. 
Larochelle M., Zhang F., Ross-Degnan D., Wharam J. "Rates of opioid dispensing and overdose after introduction of abuse-deterrent extended-release oxycodone and withdrawal of propoxyphene.” JAMA Intern Med; 175, no. 6 (2015):978-87.

Max, Mitchell B., Marilee Donovan, Christine A. Miaskowski, Sandra E. Ward, Debra Gordon, Marilyn Bookbinder, Charles S. Cleeland et al. "Quality improvement guidelines for the treatment of acute pain and cancer pain." JAMA 274, no. 23 (1995): 1874-1880.

McQuay, Henry. "Opioids in pain management." The Lancet 353, no. 9171 (1999): 2229-2232.

Model, Karyn E. "The effect of marijuana decriminalization on hospital emergency room drug episodes: 1975-1978." Journal of the American Statistical Association 88, no. 423 (1993): 737747.

Pacula, Rosalie Liccardo. "Does increasing the beer tax reduce marijuana consumption?" Journal of Health Economics 17, no. 5 (1998): 557-585.

Paulozzi, Leonard J. "Prescription drug overdoses: a review." Journal of Safety Research 43, no. 4 (2012): 283-289.

Paulozzi, Leonard J., Karin A. Mack, and Jason M. Hockenberry. "Vital signs: variation among states in prescribing of opioid pain relievers and benzodiazepines_-United States, 2012." MMWR Morb Mortal Wkly Rep 63, no. 26 (2014): 563-8.

Phillips, Donald M. "JCAHO pain management standards are unveiled." JAMA: The Journal of the American Medical Association 284, no. 4 (2000): 428-429.

Pollack, Harold A., and Peter Reuter. "Does tougher enforcement make drugs more expensive?" Addiction 109, no. 12 (2014): 1959-1966.

Powell, David, Rosalie Liccardo Pacula, and Mireille Jacobson. Do Medical Marijuana Laws Reduce Addictions and Deaths Related to Pain Killers? No. w21345. National Bureau of Economic Research (2015).

Reuter, Peter, and Mark AR Kleiman. "Risks and prices: An economic analysis of drug enforcement." Crime and Justice (1986): 289-340.

Rudd, R., Aleshire, N., Zibbell, J., and R.M. Gladden. "Increases in Drug and Opioid Overdose Deaths — United States, 2000-2014." Morbidity and Mortality Weekly Report (MMWR). 64, no. 50 (2016); 1378-82.

Saffer, Henry, and Frank Chaloupka. "The demand for illicit drugs." Economic Inquiry 37, no. 3 (1999): 401-411.

Santos Silva, JMC, and Silvana Tenreyro. "The log of gravity." The Review of Economics and Statistics 88, no. 4 (2006): 641-658 
Sessler, Nelson E., Jerod M. Downing, Hrishikesh Kale, Howard D. Chilcoat, Todd F. Baumgartner, and Paul M. Coplan. "Reductions in reported deaths following the introduction of extended-release oxycodone (OxyContin) with an abuse-deterrent formulation." Pharmacoepidemiology and Drug Safety 23, no. 12 (2014): 1238-1246.

Severtson, Stevan Geoffrey, Becki Bucher Bartelson, Jonathan M. Davis, Alvaro Munoz, Michael F. Schneider, Howard Chilcoat, Paul M. Coplan, Hilary Surratt, and Richard C. Dart. "Reduced abuse, therapeutic errors, and diversion following reformulation of extended-release oxycodone in 2010." The Journal of Pain 14, no. 10 (2013): 1122-1130.

Solon, Gary, Steven J. Haider, and Jeffrey M. Wooldridge. "What are we weighting for?" Journal of Human Resources 50, no. 2 (2015): 301-316.

Substance Abuse and Mental Health Services Administration. "Results from the 2014 National Survey on Drug Use and Health: detailed tables" (2015). Available at: http://www.samhsa.gov/data/sites/default/files/NSDUH-DetTabs2014/NSDUHDetTabs2014.pdf

Surratt, Hilary L., Catherine O'Grady, Steven P. Kurtz, Yamilka Stivers, Theodore J. Cicero, Richard C. Dart, and Minxing Chen. "Reductions in prescription opioid diversion following recent legislative interventions in Florida." Pharmacoepidemiology and drug safety 23, no. 3 (2014): 314-320.

U.S. Government Accountability Office. “OxyContin Abuse and Diversion and Efforts to Address the Problem.” (2003): GAO-04-110.

Van Amsterdam, J and W van den Brink. "The Misuse of Prescription Opioids: A Threat for Europe?” Current Drug Abuse Reviews 8 (2015): 3-14.

Warner, Margaret, H. Hedegaard, and L. H. Chen. "Trends in drug-poisoning deaths involving opioid analgesics and heroin: United States, 1999-2012."NCHS Health E-Stat (2014).

WHO Expert Committee. "Cancer pain relief." World Health Organization, Geneva (1986).

Williams, Jenny, Rosalie Liccardo Pacula, Frank J. Chaloupka, and Henry Wechsler. "Alcohol and marijuana use among college students: economic complements or substitutes?" Health Economics 13, no. 9 (2004): 825-843.

Wolfers, Justin. "Did unilateral divorce laws raise divorce rates? A reconciliation and new results." The American Economic Review 96, no. 5 (2006): 1802-1820.

Wooldridge, Jeffrey M. "Econometric analysis of cross section and panel data." Cambridge, MA: Massachusetts Institute of Technology (2002). 


\section{Figures and Tables}

\section{Figure 1: Trends in Drug Overdose Deaths: Prescription Opioids and Heroin}
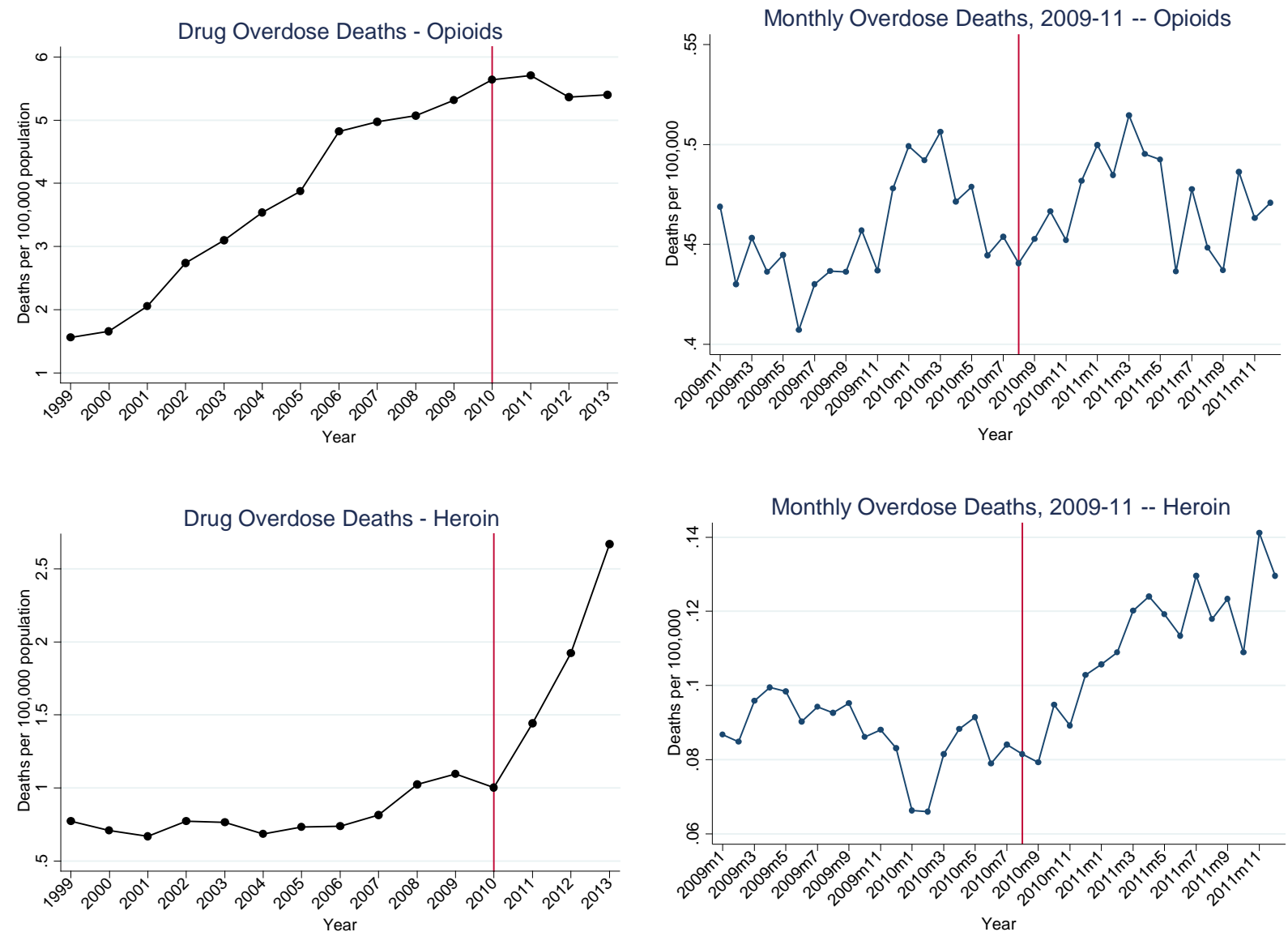

Notes: Deaths per 100,000 population from the National Vital Statistics System (NVSS). Opioid overdose deaths are coded using ICD-10 codes for underlying cause of death X40-X44, X60-X64, X85, and Y10-Y14 with a multiple cause code of T40.2 for natural and semisynthetic opioids (e.g., oxycodone and hydrocodone), T40.3 for methadone, and T40.4 for synthetic opioids excluding methadone (e.g., fentanyl and tramadol). Heroin deaths are coded using T40.1 and a drug poisoning underlying cause of death. 
Figure 2: Trends in Prescription Opioid Use

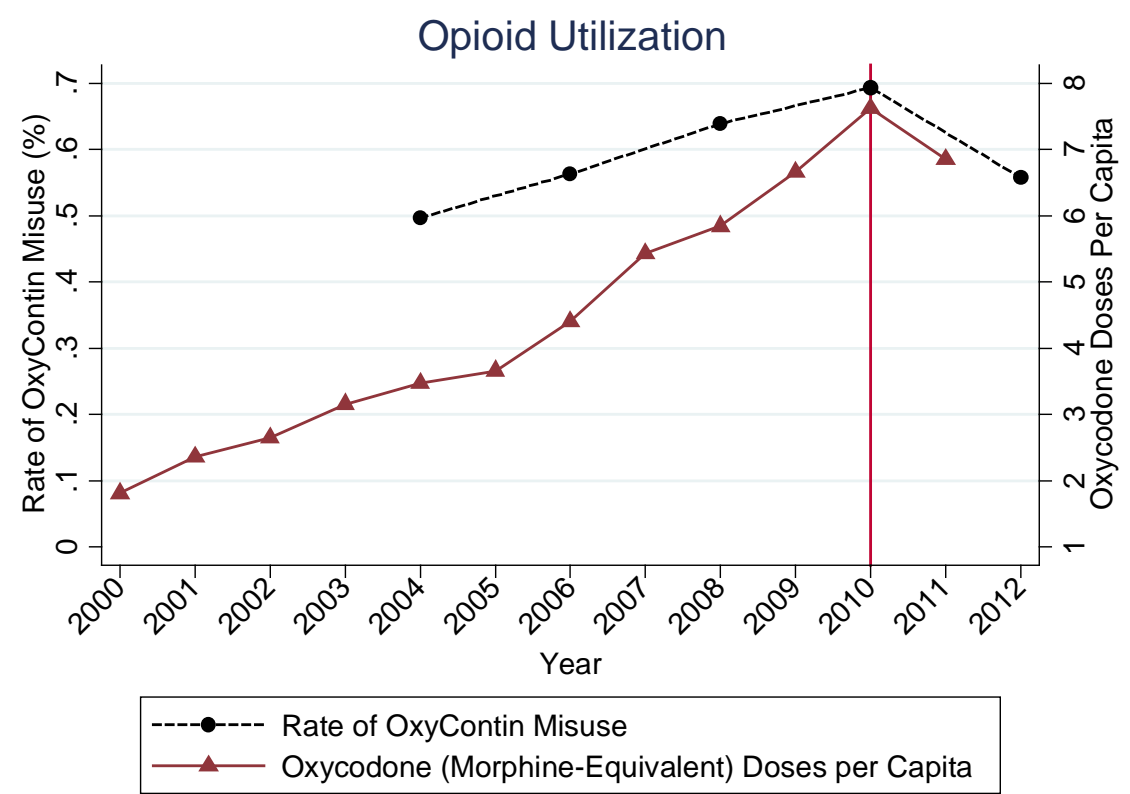

Notes: Rate of OxyContin misuse is the percentage of the population ages 12+ "using OxyContin for nonmedical use" in the National Survey on Drug Use and Health (NSDUH). The NSDUH pools consecutive years (e.g., 2004 is 2004 and 2005). Oxycodone doses are from the DEA's Automation of Reports and Consolidated Orders System (ARCOS) and have been converted into morphine-equivalent doses per capita. Oxycodone is the primary ingredient in OxyContin and is also contained in other opioid pain relievers. 
Figure 3: Geographic Variation in Rate of OxyContin Misuse, 2004-2008

Panel A: States with highest and lowest rates of OxyContin misuse

\begin{tabular}{llllr}
\hline \hline Top 10 Rates of OxyContin Misuse (\%) & & & Bottom 10 Rates of OxyContin Misuse (\%) \\
\hline Rhode Island & 1.15 & & Washington D.C. & 0.47 \\
West Virginia & 1.13 & & Minnesota & 0.47 \\
Utah & 1.04 & Georgia & 0.39 \\
Wisconsin & 0.98 & Nebraska & 0.39 \\
Massachusetts & 0.97 & Mississippi & 0.37 \\
Kentucky & 0.97 & California & 0.30 \\
Montana & 0.96 & Texas & 0.29 \\
Indiana & 0.96 & Iowa & 0.27 \\
Nevada & 0.95 & South Dakota & 0.26 \\
Alaska & 0.94 & Illinois & 0.26 \\
\hline \hline
\end{tabular}

Panel B: State variation in Rate of OxyContin Misuse

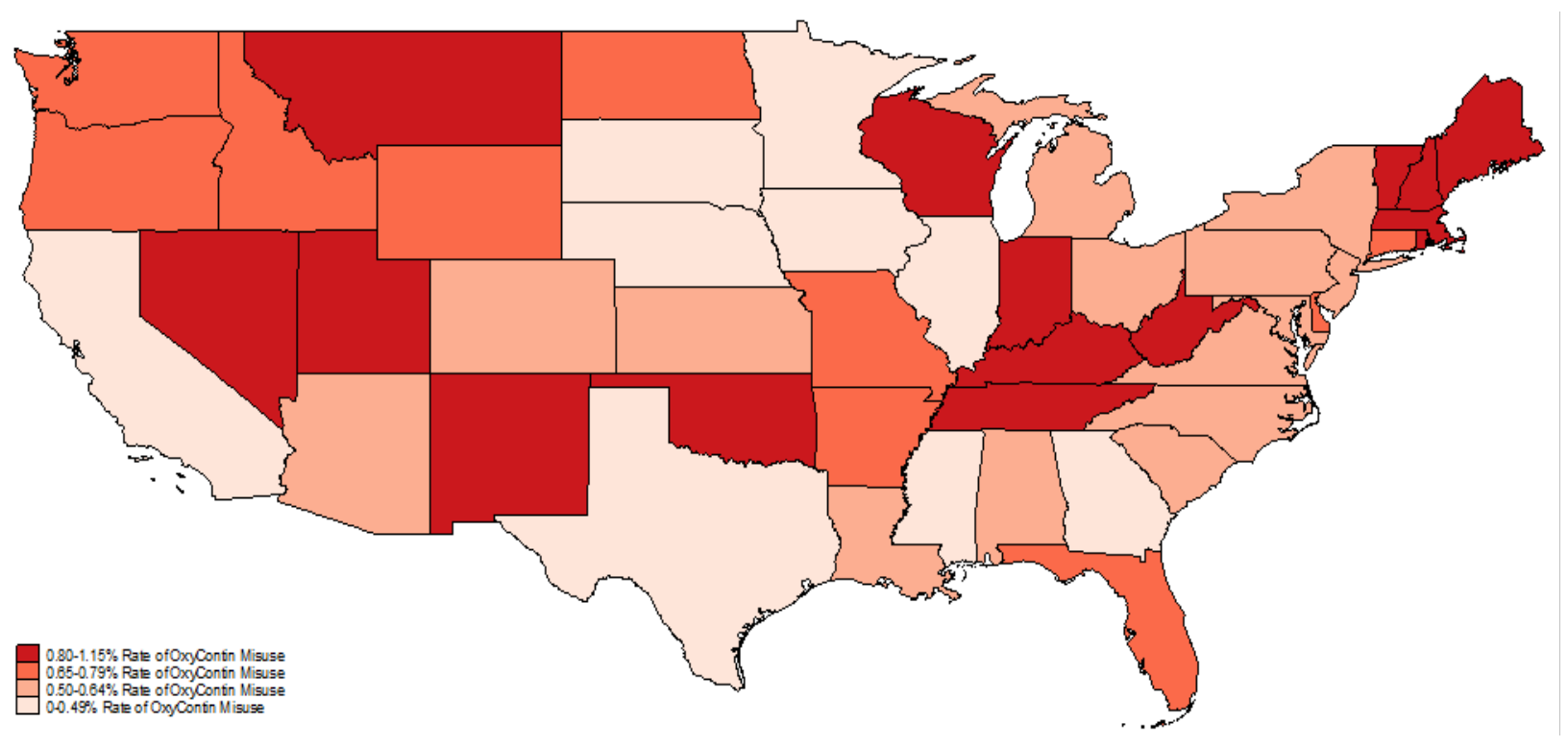


Figure 4: Relationship between Pre-Reformulation Rate of OxyContin Misuse and Change Between 2008-2012

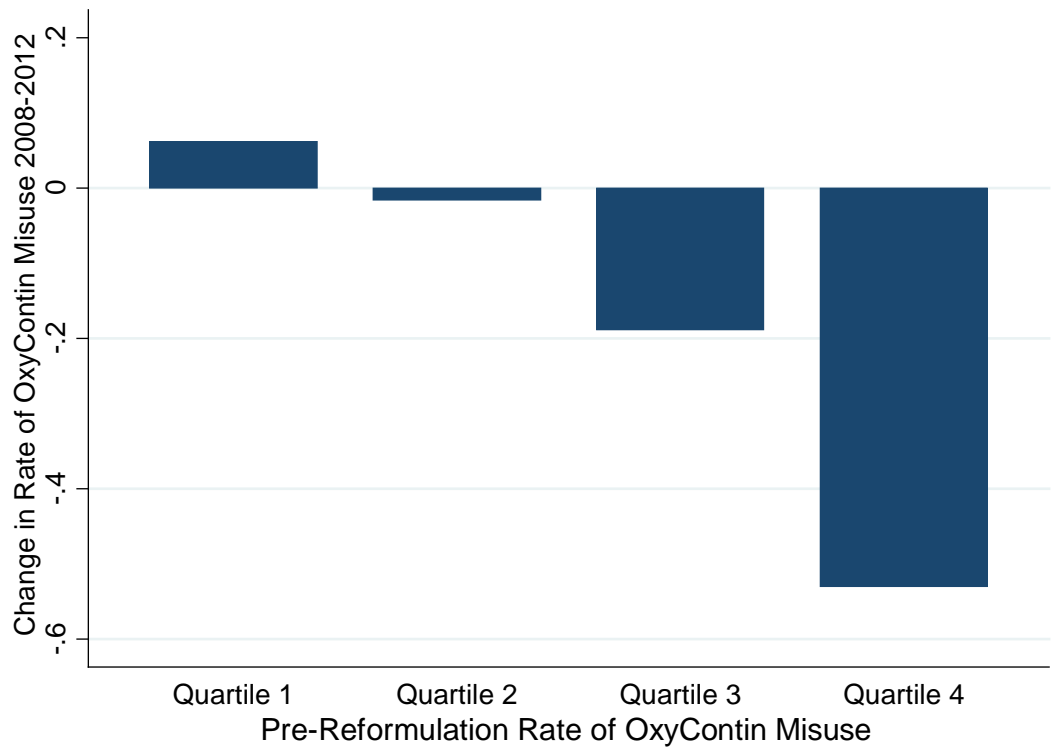

Notes: Quartiles represent states with the highest and lowest pre-reformulation rates of OxyContin misuse (Quartile 4 includes the $25 \%$ of states with the highest pre-reformulation rates of OxyContin misuse). The change in the rate of OxyContin misuse is weighted by state population. 
Figure 5: Relationship Between Initial OxyContin Misuse and Changes in OxyContin Misuse - Event Study Specification

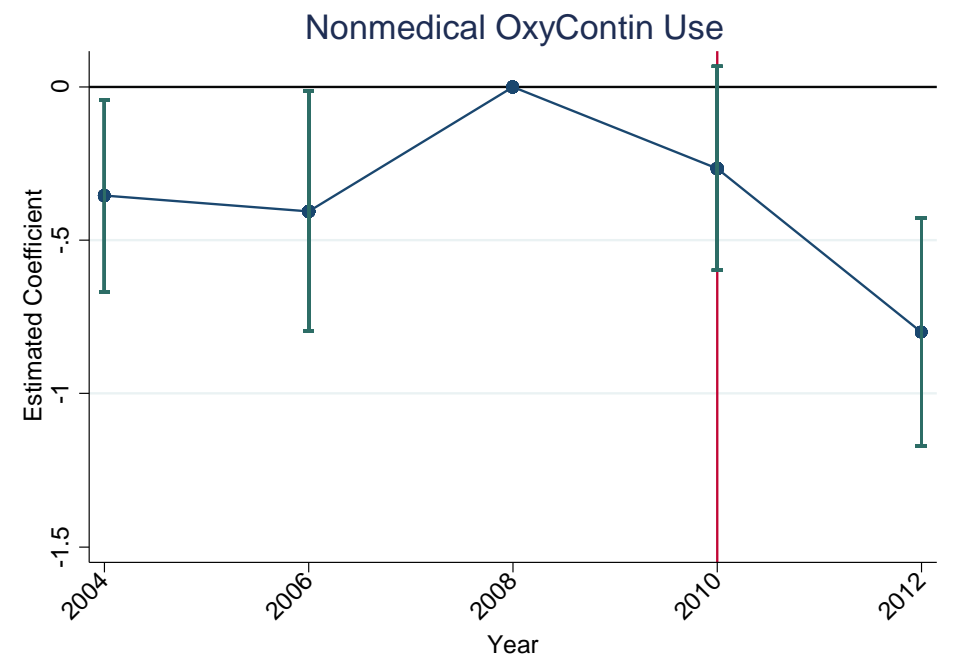

Notes: Each year on the $\mathrm{x}$-axis refers to that year and the following year since each NSDUH wave includes two years. Consequently, we should expect a partial effect in 2010 (which includes post-reformulation year 2011) and a full year effect for 2012 (and 2013). The graph reports point estimates and 95\% confidence intervals (which are adjusted for within-state clustering). 
Figure 6: Effect of OxyContin Reformulation on Overdose Deaths- Baseline Event Study Specification

Panel A: Opioid and Heroin Mortality
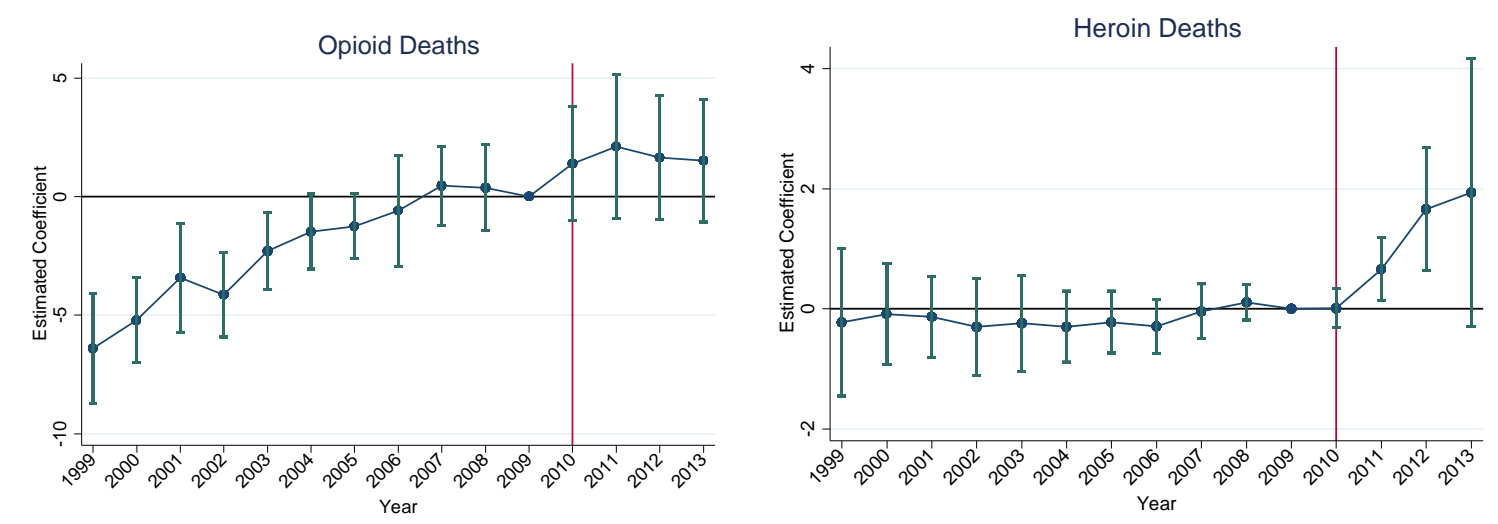

Panel B: Net Impact on Mortality
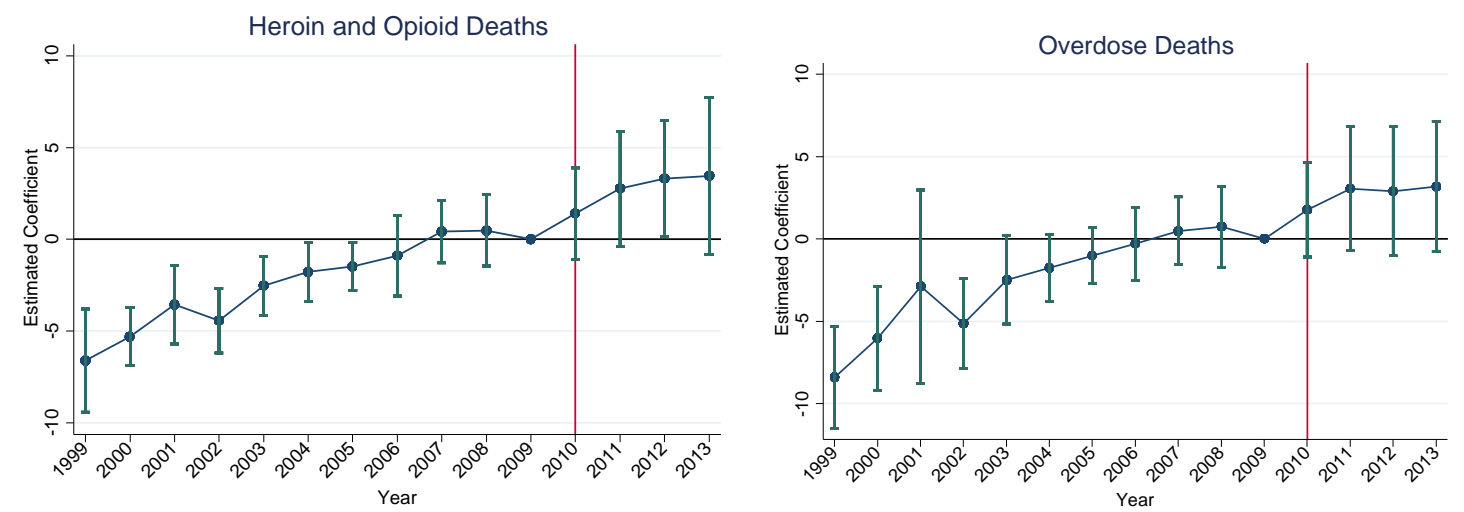

Notes: Each graph includes point estimates from event study (normalized to 0 in 2009) and 95\% confidence intervals which are adjusted for within-state clustering. 
Figure 7: Event Study Results for Heroin Deaths using Alternative Measures of the "Bite" of OxyContin Reformulation

Panel A: OxyContin Misuse/Pain Reliever Misuse (NSDUH)

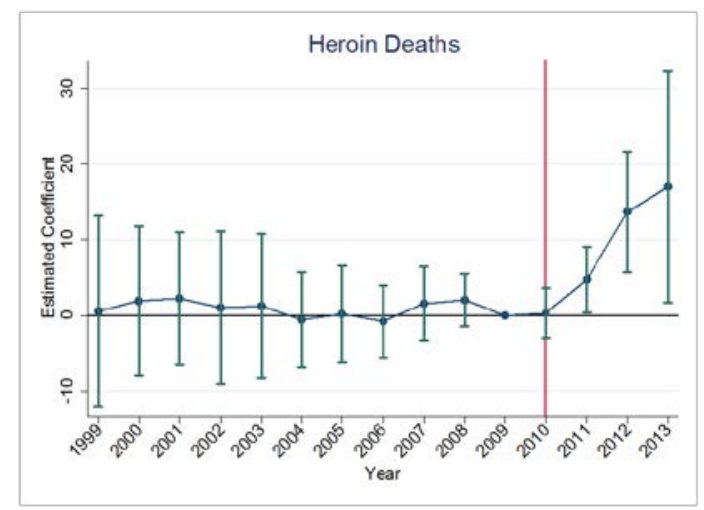

Panel B: Oxycodone/(Oxycodone+Hydrocodone) (ARCOS)

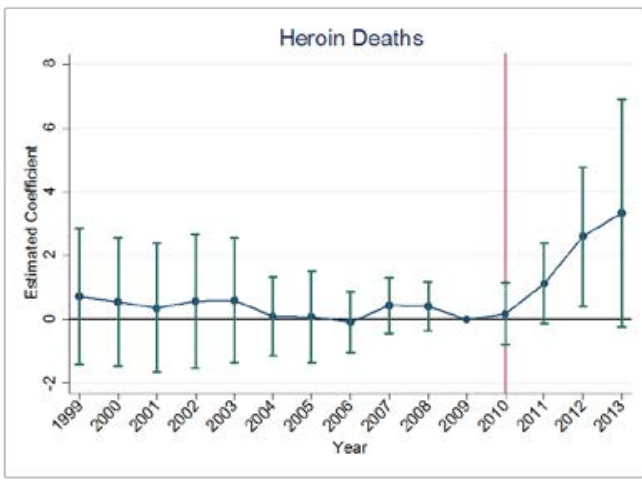

Panel C: Oxycodone/Hydrocodone (ARCOS)

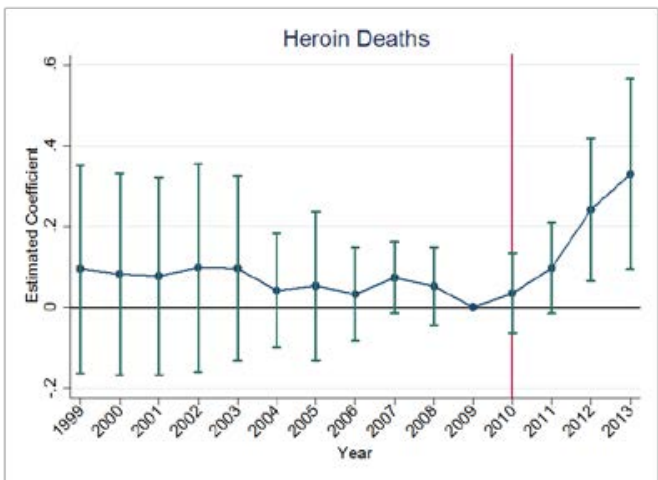

Notes: Each graph includes point estimates from event study (normalized to 0 in 2009) and 95\% confidence intervals which are adjusted for within-state clustering. 
Figure 8 - Alternative Explanations: Event Study Results for Heroin Prices and Economic Conditions

\section{Panel A: Heroin Prices}

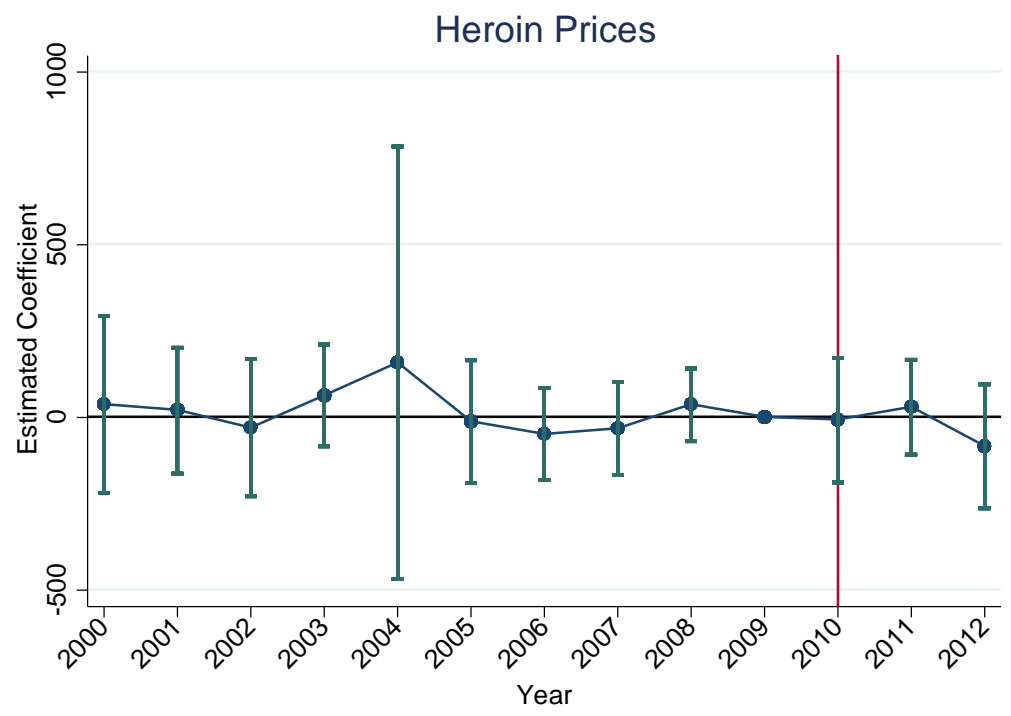

Panel B: Unemployment Rate

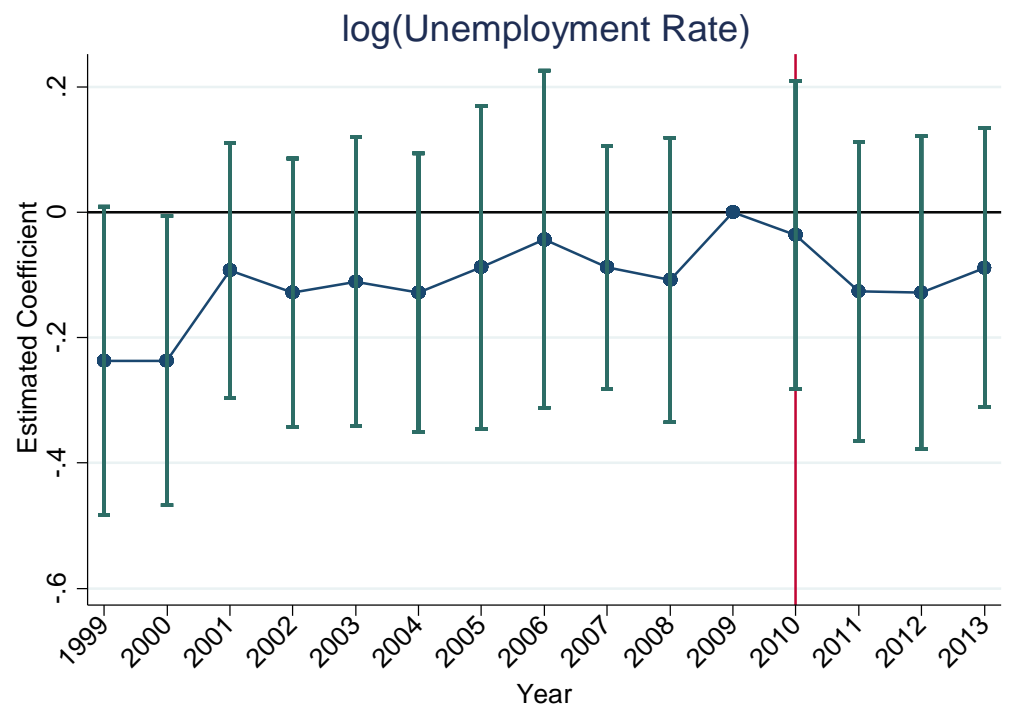


Table 1: Summary Statistics, 2000-2009

\begin{tabular}{|c|c|c|c|c|}
\hline Variable (Mean) & All States & $\begin{array}{c}\text { States with Low } \\
\text { OxyContin } \\
\text { Misuse Rate } \\
\end{array}$ & $\begin{array}{c}\text { States with High } \\
\text { OxyContin } \\
\text { Misuse Rate } \\
\end{array}$ & Source \\
\hline \multicolumn{5}{|l|}{ Outcomes } \\
\hline $\begin{array}{l}\text { Oxycontin Misuse Rate (\%) } \\
\text { Oxycodone (Morphine-Equiv }\end{array}$ & 0.567 & 0.447 & 0.842 & NSDUH, 2004-2008 \\
\hline \multicolumn{5}{|l|}{ Deaths per 100,000: } \\
\hline Opioids & 3.747 & 3.001 & 5.460 & Vital Statistics, 2000-2009 \\
\hline Heroin & 0.803 & 0.787 & 0.839 & Vital Statistics, 2000-2009 \\
\hline $\begin{array}{l}\text { All Drug Overdoses } \\
\text { Demographics Characteris }\end{array}$ & \multicolumn{3}{|c|}{ Demographics Characteristics } & Vital Statistics, 2000-2009 \\
\hline Population & $5,532,597$ & $7,888,832$ & 3,266,986 & Census, 2000 \\
\hline \multicolumn{5}{|l|}{ Age (\%): } \\
\hline $0-17$ & 25.65 & 25.98 & 24.88 & Census, 2000 \\
\hline $18-64$ & 61.92 & 62.08 & 61.55 & Census, 2000 \\
\hline $65^{+}$ & 12.43 & 11.94 & 13.57 & Census, 2000 \\
\hline \multicolumn{5}{|l|}{ Race (\%): } \\
\hline White & 80.99 & 78.64 & 86.45 & Census, 2000 \\
\hline Black & 12.69 & 14.41 & 8.70 & Census, 2000 \\
\hline Other Race & 6.31 & 6.94 & 4.85 & Census, 2000 \\
\hline Unemployment Rate (\%) & 4.01 & 4.12 & 3.76 & BLS, 2000 \\
\hline Personal Income Per Capita & $30,318.88$ & $30,840.44$ & 29,107.92 & BEA, 2000 \\
\hline Poverty Rate (\%) & 11.32 & 11.55 & 10.79 & Census, 2000 \\
\hline Number of States & 51 & 25 & 26 & \\
\hline
\end{tabular}

Notes: Means are weighted by state population and pooled for 2000-2009 unless otherwise noted. 
Table 2: Relationship Between OxyContin Misuse and Changes in Heroin Death Rates

\begin{tabular}{lccc|cc}
\hline \hline \multicolumn{1}{c}{ Outcome: } & \multicolumn{5}{c}{ Heroin Deaths per 100,000 } \\
\cline { 2 - 6 } & $(1)$ & $(2)$ & $(3)$ & $(4)$ & $(5)$ \\
Initial OxyContin (3 Year Effect) & $2.212^{* *}$ & $2.537^{* * *}$ & $3.466^{* * *}$ & 1.254 & $1.732^{* *}$ \\
& $(0.905)$ & $(0.897)$ & $(1.005)$ & $(0.773)$ & $(0.761)$ \\
Initial Pain Reliever (3 Year Effect) & & & $-0.414^{* *}$ & & $-0.352^{* * *}$ \\
& & & $(0.199)$ & & $(0.137)$ \\
Mean of Dep. Variable (2008-09): & 1.060 & & & & \\
\hline State-Varying Covariates & No & Yes & Yes & Yes & Yes \\
Estimator & OLS & OLS & OLS & Poisson & Poisson \\
\hline
\end{tabular}

Notes: *10\% Significance, $* * 5 \%$ Significance, $* * * 1 \%$ Significance. Standard errors in parentheses adjusted for clustering at the state-level. State fixed effects and year fixed effects included in all specifications. Each model also includes a linear trend interacted with initial nonmedical OxyContin misuse as well as a post-2011 indicator interacted with initial nonmedical OxyContin misuse. Finally, a separate post-2011 linear trend interacted with initial nonmedical OxyContin misuse is also included. We report the 3 year post-2011 effect of the initial OxyContin variable. Regressions are weighted by population. Years 2008-2013 are used. 
Table 3: Relationship Between OxyContin Misuse and Changes in Opioid Death Rates

\begin{tabular}{|c|c|c|c|c|c|}
\hline \multirow[t]{2}{*}{ Outcome: } & \multicolumn{5}{|c|}{ Overdose Deaths per 100,000 } \\
\hline & (1) & (2) & (3) & (4) & (5) \\
\hline \multicolumn{6}{|c|}{ A. Total Opioid Deaths per $100,000($ T40.2-T40.4) } \\
\hline Initial OxyContin (3 Year Effect) & $\begin{array}{l}-1.135 \\
(1.712)\end{array}$ & $\begin{array}{l}-0.815 \\
(1.624)\end{array}$ & $\begin{array}{c}0.019 \\
(1.922)\end{array}$ & $\begin{array}{c}0.007 \\
(0.344)\end{array}$ & $\begin{array}{c}0.051 \\
(0.403)\end{array}$ \\
\hline Initial Pain Reliever (3 Year Effect) & & & $\begin{array}{c}-0.375 \\
(0.403)\end{array}$ & & $\begin{array}{l}-0.036 \\
(0.072)\end{array}$ \\
\hline Mean of Dep. Variable (2008-09): & 5.192 & & & & \\
\hline \multicolumn{6}{|c|}{ B. Natural Opioid Deaths per 100,000 (T40.2) } \\
\hline Initial OxyContin (3 Year Effect) & $\begin{array}{l}-2.699 \\
(1.682)\end{array}$ & $\begin{array}{l}-2.554 \\
(1.650)\end{array}$ & $\begin{array}{l}-2.287 \\
(1.901)\end{array}$ & $\begin{array}{c}-0.751^{*} \\
(0.447)\end{array}$ & $\begin{array}{l}-0.774 \\
(0.489)\end{array}$ \\
\hline Initial Pain Reliever (3 Year Effect) & & & $\begin{array}{l}-0.116 \\
(0.373)\end{array}$ & & $\begin{array}{c}0.030 \\
(0.094)\end{array}$ \\
\hline Mean of Dep. Variable (2008-09): & 3.233 & & & & \\
\hline \multicolumn{6}{|c|}{ C. Natural Opioid-Only Deaths per 100,000 (T40.2, but not also T40.3 or T40.4) } \\
\hline Initial OxyContin (3 Year Effect) & $\begin{array}{c}-2.505^{*} \\
(1.448)\end{array}$ & $\begin{array}{c}-2.387^{*} \\
(1.431)\end{array}$ & $\begin{array}{c}-2.202 \\
(1.664)\end{array}$ & $\begin{array}{c}-0.876^{*} \\
(0.480)\end{array}$ & $\begin{array}{l}-0.915 * \\
(0.519)\end{array}$ \\
\hline Initial Pain Reliever (3 Year Effect) & & & $\begin{array}{l}-0.079 \\
(0.327)\end{array}$ & & $\begin{array}{c}0.044 \\
(0.096)\end{array}$ \\
\hline Mean of Dep. Variable (2008-09): & 2.73 & & & & \\
\hline $\begin{array}{l}\text { State-Varying Covariates } \\
\text { Sta }\end{array}$ & No & Yes & Yes & Yes & Yes \\
\hline Estimator & OLS & OLS & OLS & Poisson & Poisson \\
\hline
\end{tabular}

Notes: *10\% Significance, $* * 5 \%$ Significance, $* * * 1 \%$ Significance. Standard errors in parentheses adjusted for clustering at the state-level. State fixed effects and year fixed effects included in all specifications. Each model also includes a linear trend interacted with initial nonmedical OxyContin misuse as well as a post-2011 indicator interacted with initial nonmedical OxyContin misuse. Finally, a separate post-2011 linear trend interacted with initial nonmedical OxyContin misuse is also included. We report the 3 year post-2011 effect of the initial OxyContin variable. Regressions are weighted by population. Years 2008-2013 are used. 
Table 4: OxyContin Misuse and Changes in Synthetic Opioid Death Rates

\begin{tabular}{|c|c|c|c|c|c|}
\hline \multirow[t]{2}{*}{ Outcome: } & \multicolumn{5}{|c|}{ Overdose Deaths per 100,000} \\
\hline & (1) & $(2)$ & (3) & (4) & (5) \\
\hline \multicolumn{6}{|c|}{ A. Synthetic Opioid Deaths per 100,000 (T40.4) } \\
\hline Initial OxyContin (3 Year Effect) & $\begin{array}{c}0.454 \\
(0.360)\end{array}$ & $\begin{array}{c}0.492 \\
(0.387)\end{array}$ & $\begin{array}{c}0.868^{* *} \\
(0.423)\end{array}$ & $\begin{array}{c}1.237 * * * \\
(0.366)\end{array}$ & $\begin{array}{c}1.494 * * * \\
(0.373)\end{array}$ \\
\hline Initial Pain Reliever (3 Year Effect) & & & $\begin{array}{l}-0.169 \\
(0.105)\end{array}$ & & $\begin{array}{c}-0.169 * * \\
(0.071)\end{array}$ \\
\hline Mean of Dep. Variable (2008-09): & 0.887 & & & & \\
\hline \multicolumn{6}{|c|}{ B. Synthetic Opioid-Only Deaths per 100,000 (T40.4, but not also T40.2 or T40.3) } \\
\hline Initial OxyContin (3 Year Effect) & $\begin{array}{c}0.228 \\
(0.237)\end{array}$ & $\begin{array}{c}0.257 \\
(0.257)\end{array}$ & $\begin{array}{c}0.528 * * \\
(0.261)\end{array}$ & $\begin{array}{c}1.196^{* * *} \\
(0.334)\end{array}$ & $\begin{array}{c}1.444^{* * *} \\
(0.330)\end{array}$ \\
\hline Initial Pain Reliever (3 Year Effect) & & & $\begin{array}{c}-0.123^{*} \\
(0.070)\end{array}$ & & $\begin{array}{c}-0.166 * * * \\
(0.062)\end{array}$ \\
\hline Mean of Dep. Variable (2008-09): & 0.631 & & & & \\
\hline State-Varying Covariates & No & Yes & $\mathrm{Ye}$ & Yes & Yes \\
\hline Estimator & OLS & OLS & OLS & Poisson & Poisson \\
\hline
\end{tabular}

Notes: $* 10 \%$ Significance, $* * 5 \%$ Significance, $* * * 1 \%$ Significance. Standard errors in parentheses adjusted for clustering at the state-level. State fixed effects and year fixed effects included in all specifications. Each model also includes a linear trend interacted with initial nonmedical OxyContin misuse as well as a post-2011 indicator interacted with initial nonmedical OxyContin misuse. Finally, a separate post-2011 linear trend interacted with initial nonmedical OxyContin misuse is also included. We report the 3 year post-2011 effect of the initial OxyContin variable. Regressions are weighted by population. Years 2008-2013 are used. 
Table 5: Relationship Between OxyContin Misuse and Changes in Overall Overdose Death Rates

\begin{tabular}{lccc|cc}
\hline \hline \multicolumn{1}{c}{ Outcome: } & \multicolumn{5}{c}{ Overdose Deaths per 100,000 } \\
\cline { 2 - 6 } & $(1)$ & $(2)$ & $(3)$ & $(4)$ & $(5)$ \\
A. Opioid and Heroin Deaths & & & & & \\
Initial OxyContin (3 Year Effect) & 1.077 & 1.722 & 3.485 & 0.159 & 0.304 \\
& $(2.172)$ & $(2.020)$ & $(2.419)$ & $(0.364)$ & $(0.444)$ \\
Initial Pain Reliever (3 Year Effect) & & & -0.789 & & -0.116 \\
& & & $(0.538)$ & & $(0.084)$ \\
Mean of Dep. Variable (2008-09): & 6.252 & & & & \\
B. Total Overdose Deaths (All Causes) & & & & \\
Initial OxyContin (3 Year Effect) & 0.205 & 0.930 & 2.822 & 0.017 & 0.087 \\
& $(2.650)$ & $(2.764)$ & $(3.446)$ & $(0.274)$ & $(0.336)$ \\
Initial Pain Reliever (3 Year Effect) & & & -0.839 & & -0.072 \\
& & & $(0.644)$ & & $(0.058)$ \\
Mean of Dep. Variable (2008-09): & 13.097 & & & & Yes \\
\hline State-Varying Covariates & No & Yes & Yes & Yes & Poisson \\
Estimator & OLS & OLS & OLS & Poisson \\
\hline
\end{tabular}

Notes: *10\% Significance, **5\% Significance, ***1\% Significance. Standard errors in parentheses adjusted for clustering at the state-level. State fixed effects and year fixed effects included in all specifications. Each model also includes a linear trend interacted with initial nonmedical OxyContin misuse as well as a post-2011 indicator interacted with initial nonmedical OxyContin misuse. Finally, a separate post-2011 linear trend interacted with initial nonmedical OxyContin misuse is also included. We report the 3 year post-2011 effect of the initial OxyContin variable. Regressions are weighted by population. Years 2008-2013 are used. 


\section{Table 6: Alternative Explanations for Increase in Heroin Deaths}

\begin{tabular}{|c|c|c|c|c|c|c|}
\hline \multirow[t]{2}{*}{ Outcome: } & \multicolumn{6}{|c|}{ Heroin Deaths per 100,000 } \\
\hline & Main Result & Add PDMP & Must Access & No FL & No Pill Mill States & West Only \\
\hline Initial OxyContin (3 Year Effect) & $\begin{array}{c}2.537 * * * \\
(0.897)\end{array}$ & $\begin{array}{l}2.890 * * \\
(0.923)\end{array}$ & $\begin{array}{c}2.101^{* *} \\
(0.911)\end{array}$ & $\begin{array}{c}2.563 * * * \\
(0.951)\end{array}$ & $\begin{array}{l}2.062 * * \\
(0.970)\end{array}$ & $\begin{array}{c}3.114^{* * *} \\
(0.685)\end{array}$ \\
\hline Mean of Dep. Variable (2008-09) & 1.060 & 1.060 & 1.060 & 1.091 & 1.101 & 1.187 \\
\hline Number of Observations & 306 & 306 & 300 & 300 & 288 & 78 \\
\hline
\end{tabular}

Notes: *10\% Significance, $* * 5 \%$ Significance, $* * * 1 \%$ Significance. Standard errors in parentheses adjusted for clustering at the state-level. State fixed effects, year fixed effects, and additional covariates are included in all specifications. Each model also includes a linear trend interacted with initial nonmedical OxyContin misuse as well as a post-2011 indicator interacted with initial nonmedical OxyContin misuse. Finally, a separate post-2011 linear trend interacted with initial nonmedical OxyContin misuse is also included. We report the 3 year post-2011 effect of the initial OxyContin variable. Regressions are weighted by population. "No Pill Mill States" means that Florida, Kentucky, and West Virginia are excluded. "West Only" means that only states in the West Census Region are included in the sample. 


\section{Appendix Tables and Figures - FOR ONLINE PUBLICATION}

\section{Appendix Figure A.1: Alternative Measures of OxyContin Misuse Rate}

Panel A: Relationship between 2004-2008 OxyContin Misuse and 2004 OxyContin Misuse

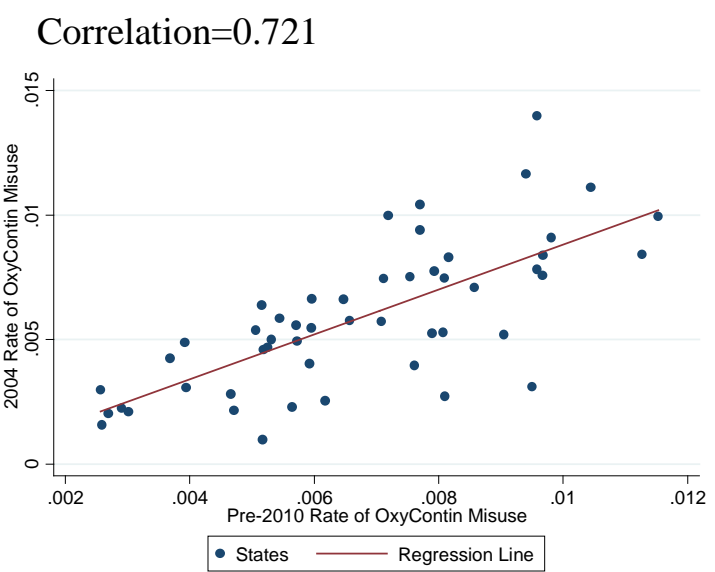

Panel B: Relationship between 2004-2008 OxyContin Misuse and 2008 OxyContin Misuse

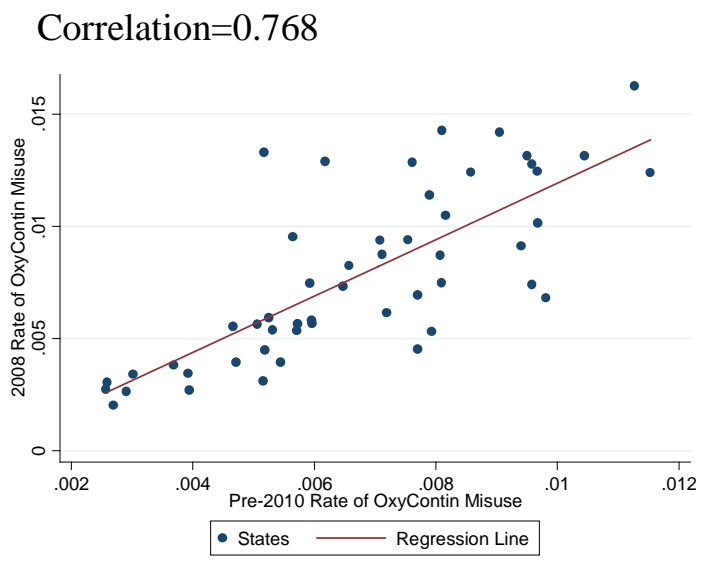

Panel C: Relationship between 2004-2008 OxyContin Misuse and 2004-2008 Oxycodone Doses

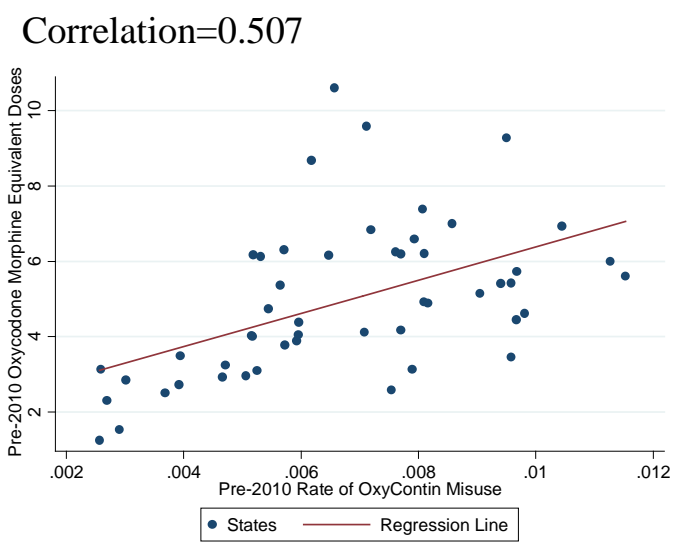




\section{Appendix Figure A.2: Poisson Event Study Specification}
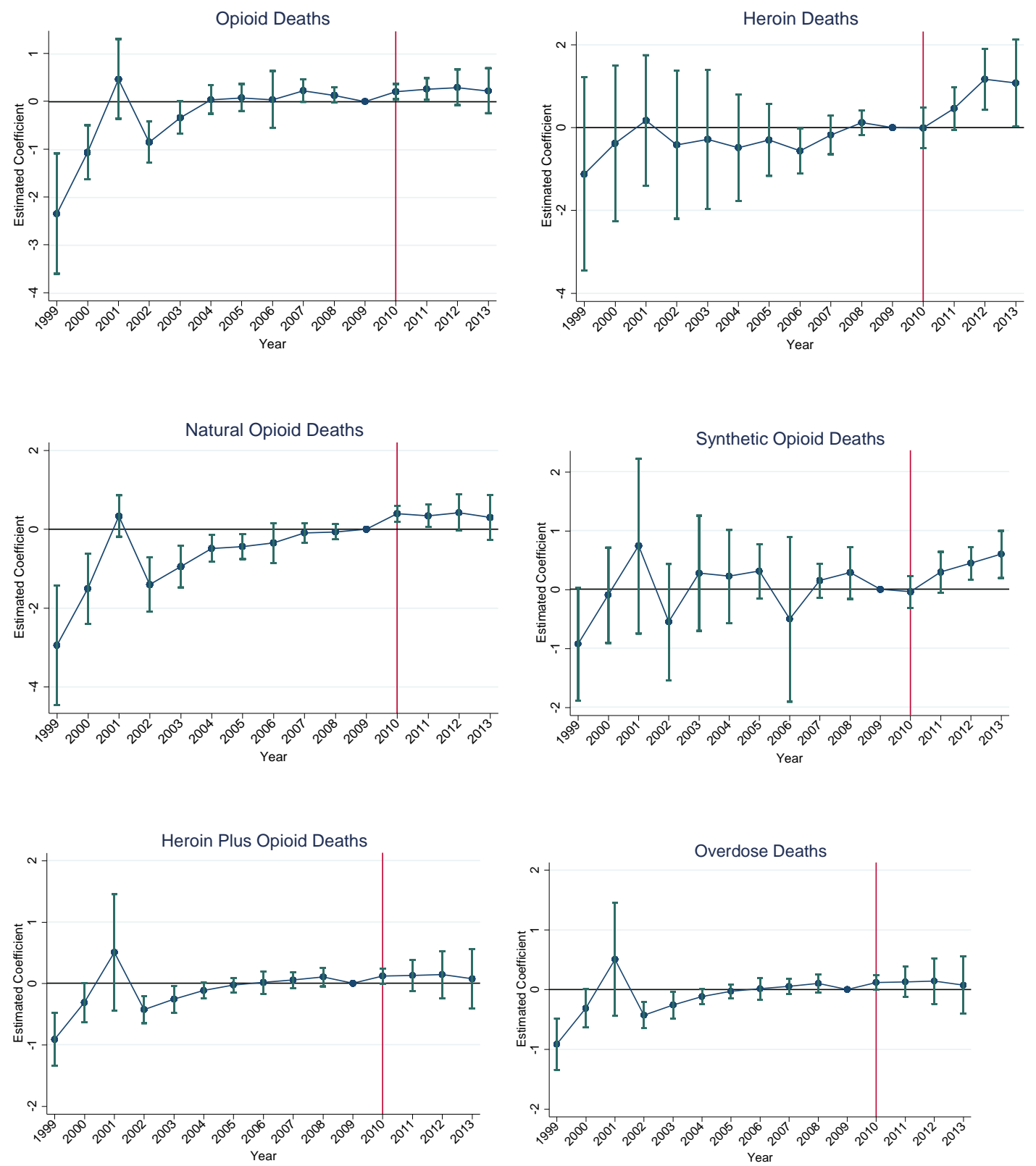

Notes: Each graph includes point estimates from event study (normalized to 0 in 2009) and 95\% confidence intervals which are adjusted for within-state clustering. 


\section{Appendix Figure A.3: Baseline Event Study Specification for Different Types of Opioid Deaths}
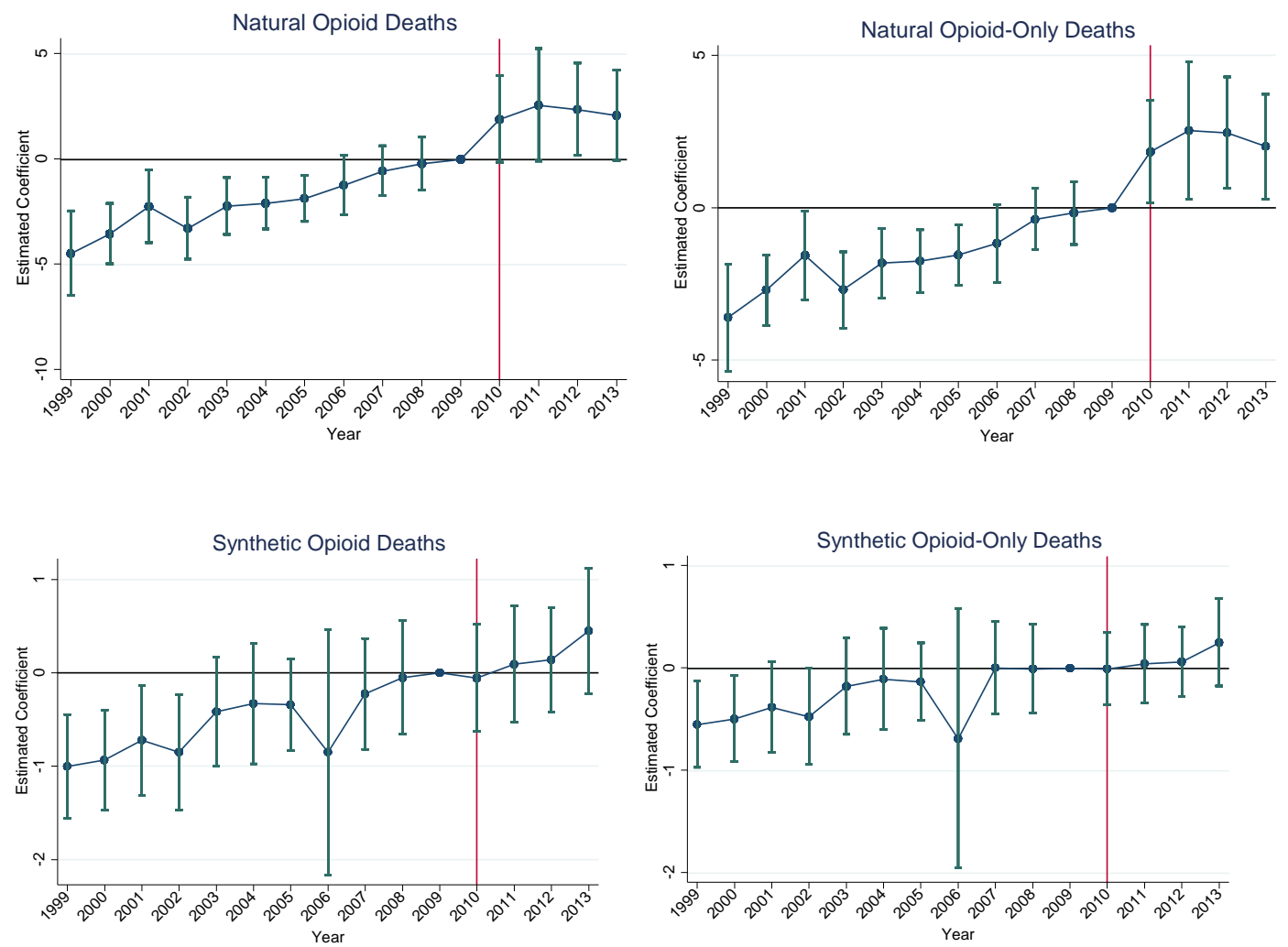

Notes: In the top figures, the left figure includes all drug overdoses involving T40.2 and the right figure uses the same outcome but excludes overdoses that also involve T40.3 or T40.4. In the bottom figures, the left figure includes all drug overdoses involving T40.4 and the right figure uses the same outcome but excludes T40.2 or T40.3. 


\section{Appendix Figure A.4 - Instrumental Variables Event Study Specification for Heroin Deaths}

Panel A: Effects of Initial OxyContin Misuse

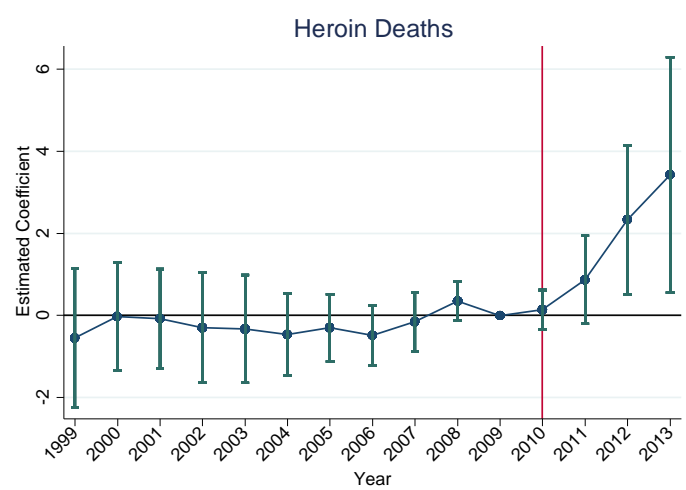

Panel B: Jointly Estimating Effects of Initial OxyContin and Pain Reliever Misuse
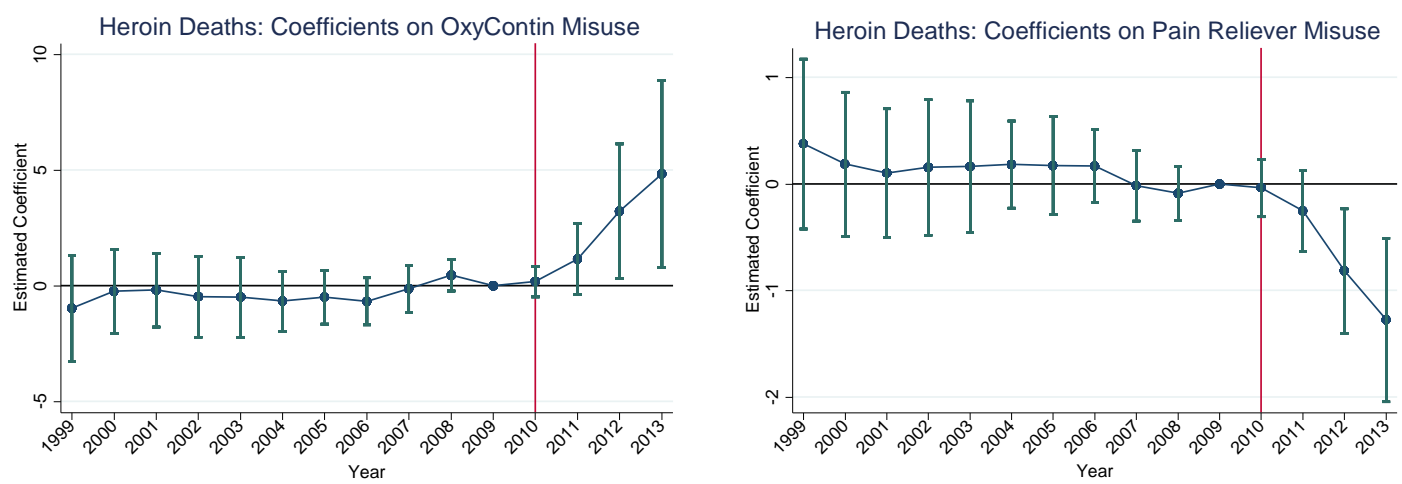

Notes: The graph on the left shows the estimates and 95\% confidence intervals for the 2008 nonmedical OxyContin misuse variable for each sample. The graph on the right shows the estimates and $95 \%$ confidence intervals for the 2008 nonmedical pain reliever misuse variable for each sample. The estimates in both figures are jointly estimated. The specification uses the 2004 nonmedical OxyContin misuse rates and 2004 nonmedical pain reliever misuse rates interacted with year indicators as instruments. 
Appendix Figure A.5: Placebo Tests - Effect of Reformulation on Other Types of Drug Overdoses

\section{Panel A: Cocaine Overdoses}

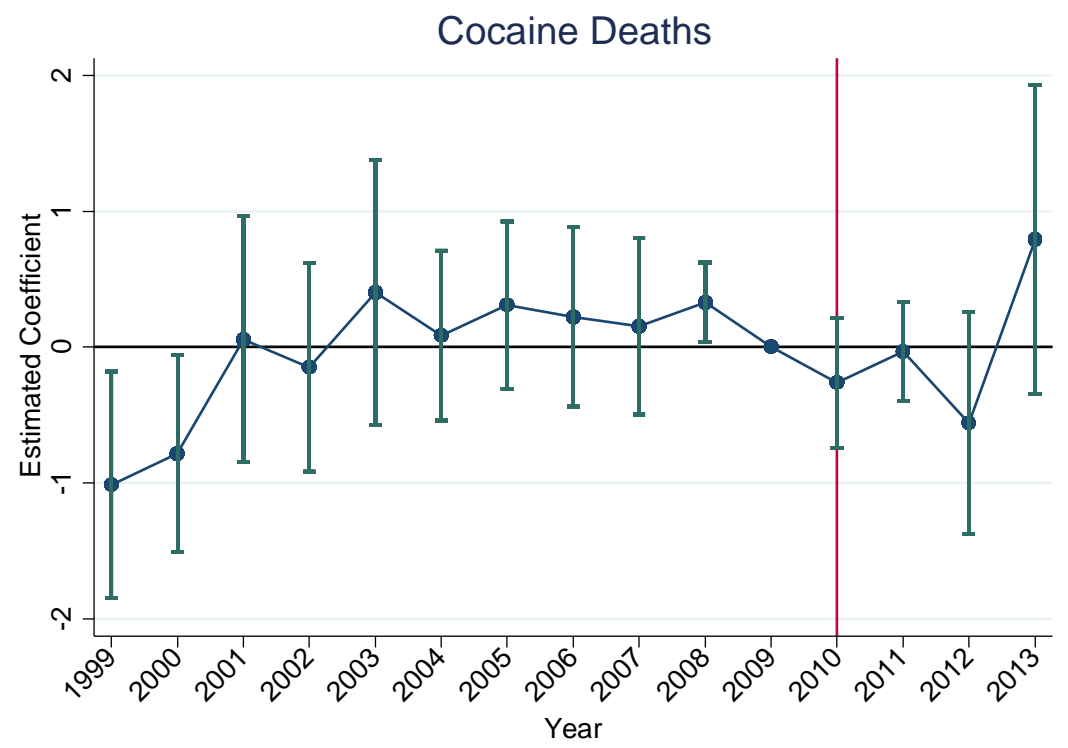

Panel B: All Drug Overdoses, Excluding Heroin and Opioids

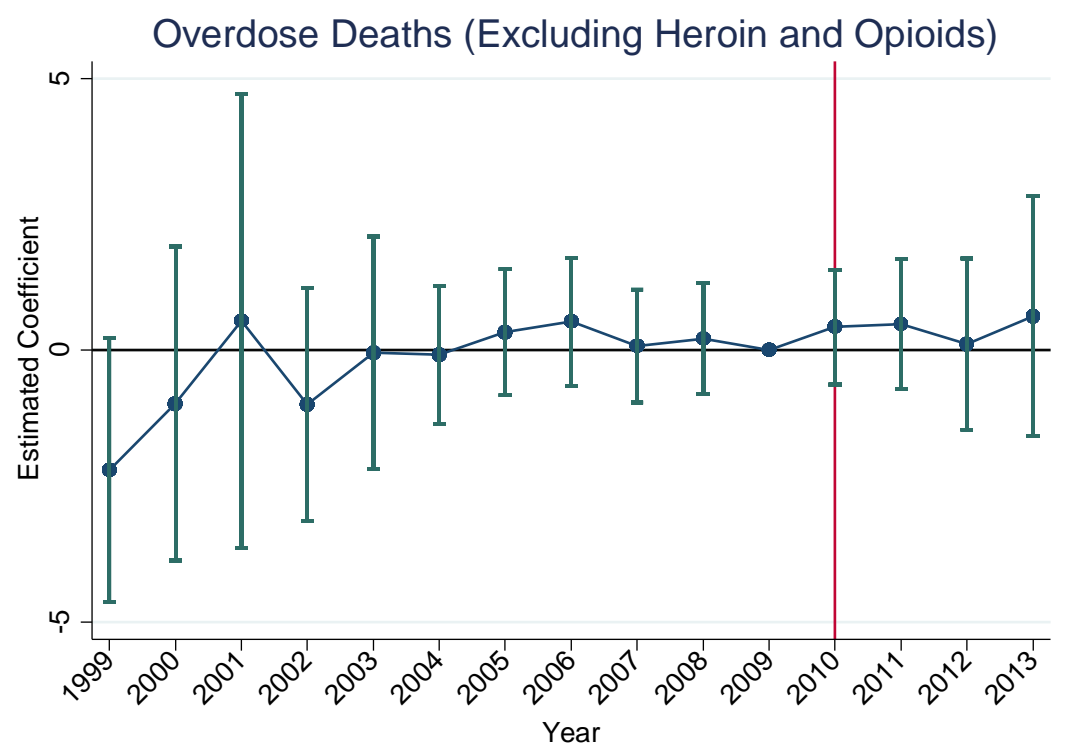




\section{Appendix Table A1: Relationship between Legal Opioid Supply (ARCOS) and Pain Reliever Misuse Rates (NSDUH)}

\begin{tabular}{ccc}
\hline \hline & OxyContin misuse & Other Pain Reliever misuse \\
\hline & $(1)$ & $(2)$ \\
Per Capita oxycodone MED & $0.071^{* * *}$ & 0.025 \\
& $(0.020)$ & $(0.078)$ \\
Per Capita hydrocodone MED & 0.026 & $0.580^{* * *}$ \\
& $(0.025)$ & $(0.143)$ \\
$\mathrm{N}$ & 51 & 51 \\
\hline \hline
\end{tabular}

Notes: $* 10 \%$ Significance, $* * 5 \%$ Significance, $* * * 1 \%$ Significance. Heteroskedastic-robust standard errors shown in parentheses. $\mathrm{MED}=$ morphine equivalent doses. Results are from cross-sectional regressions. All variables are constructed by averaging over 2004-2009 data. 


\section{Appendix Table A2: Robustness Tests for Baseline Estimates for Opioid and Heroin Deaths}

Panel A: Heroin Deaths

\begin{tabular}{lcccccccc}
\hline \multicolumn{1}{c}{ Outcome: } & \multicolumn{7}{c}{ Heroin Deaths per 100,000 } \\
\cline { 2 - 9 } & $(1)$ & $(2)$ & $(3)$ & $(4)$ & $(5)$ & $(6)$ & $(7)$ & $(8)$ \\
Initial OxyContin (3 Year Effect) & $2.537^{* * *}$ & $2.858^{* *}$ & $3.674 * * *$ & $1.876^{* *}$ & $2.099^{* *}$ & $2.412^{* * *}$ & $1.354^{* *}$ & $2.692^{* * *}$ \\
& $(0.897)$ & $(1.374)$ & $(1.180)$ & $(0.768)$ & $(0.938)$ & $(0.745)$ & $(0.690)$ & $(0.920)$ \\
\hline State Linear Trends & No & No & No & Yes & No & No & No & No \\
Weighted & Yes & Yes & No & Yes & Yes & Yes & Yes & Yes \\
Years & $2008-2013$ & No 2010 & $2008-2013$ & $2008-2013$ & $1999-2013$ & $2008-2013$ & $2008-20132008-2013$ \\
Initial Abuse Measure & $2004-2008$ & $2004-2008$ & $2004-2008$ & $2004-2008$ & $2004-2008$ & 2004 & 2008 & $2004-2008$ \\
Age-Adjusted & No & No & No & No & No & No & No & Yes \\
\hline
\end{tabular}

Panel B: Opioid Deaths

\begin{tabular}{lcccccccc}
\hline \multicolumn{1}{c}{ Outcome: } & \multicolumn{7}{c}{ Opioid Deaths per 100,000 } \\
\cline { 2 - 9 } & $(1)$ & $(2)$ & $(3)$ & $(4)$ & $(5)$ & $(6)$ & $(7)$ & $(8)$ \\
Initial OxyContin (3 Year Effect) & -0.815 & 3.65 & 0.956 & -0.910 & $-2.191 * *$ & 0.835 & -1.244 & -0.815 \\
& $(1.624)$ & $(4.925)$ & $(1.854)$ & $(1.621)$ & $(0.859)$ & $(1.561)$ & $(1.117)$ & $(1.686)$ \\
\hline State Linear Trends & No & No & No & Yes & No & No & No & No \\
Weighted & Yes & Yes & No & Yes & Yes & Yes & Yes & Yes \\
Years & $2008-2013$ & No 2010 & $2008-2013$ & $2008-2013$ & $1999-2013$ & $2008-2013$ & $2008-2013$ & $2008-2013$ \\
Initial Abuse Measure & $2004-2008$ & $2004-2008$ & $2004-2008$ & $2004-2008$ & $2004-2008$ & 2004 & 2008 & $2004-2008$ \\
Age-Adjusted & No & No & No & No & No & No & No & Yes \\
\hline
\end{tabular}

Notes: $* 10 \%$ Significance, $* * 5 \%$ Significance, $* * * 1 \%$ Significance. Standard errors in parentheses adjusted for clustering at the state-level. State fixed effects, year fixed effects, and additional covariates are included in all specifications. Each model also includes a linear trend interacted with initial nonmedical OxyContin misuse as well as a post-2011 indicator interacted with initial nonmedical OxyContin misuse. Finally, a separate post-2011 linear trend interacted with initial nonmedical OxyContin misuse is also included. We report the 3 year post-2011 effect of the initial OxyContin variable. Regressions are weighted by population unless noted otherwise. "Age Adjusted" uses an age-adjusted version of the outcome variable by weighting age-specific mortality rates, holding the weights constant across states and time. 


\section{Appendix Table A3: IV Estimates using Alternative Measures of OxyContin Misuse}

\begin{tabular}{lcc|cc}
\hline \hline & \multicolumn{2}{c}{ Heroin } & \multicolumn{2}{c}{ Opioids } \\
\cline { 2 - 5 } Initial OxyContin (3 Year Effect) & $4.077^{* * *}$ & $5.606^{* *}$ & 1.44 & 2.989 \\
& $(1.392)$ & $(2.369)$ & $(2.601)$ & $(3.966)$ \\
Initial Pain Reliever (3 Year Effect) & & $-1.366^{* *}$ & & -1.374 \\
& & $(0.655)$ & \multicolumn{2}{c}{$(0.976)$} \\
\hline Years & $2008-2013$ & $2008-2013$ & $2008-2013$ & $2008-2013$ \\
Initial Abuse Measure & 2008 & 2008 & 2008 & 2008 \\
Estimator & IV & IV & IV & IV \\
\hline
\end{tabular}

Notes: *10\% Significance, **5\% Significance, $* * * 1 \%$ Significance. Standard errors in parentheses adjusted for clustering at the state-level. State fixed effects, year fixed effects, and additional covariates are included in all specifications. Each model also includes a linear trend interacted with initial nonmedical OxyContin misuse as well as a post-2011 indicator interacted with initial nonmedical OxyContin misuse. Finally, a separate post-2011 linear trend interacted with initial nonmedical OxyContin misuse is also included. We report the 3 year post-2011 effect of the initial OxyContin variable. Regressions are weighted by population. IV estimation is used in which the instruments are the same variables using the 2004 measures of initial nonmedical use. 


\section{Appendix Table A4: Alternative Explanations: Opioid Deaths}

\begin{tabular}{lcccccccc}
\hline \multirow{2}{*}{ Outcome: } & \multicolumn{7}{c}{ Opioid Deaths per } & 100,000 \\
\cline { 2 - 4 } & Main Result & Add PDMP & Must Access & No FL & No Pill Mill States & West Only \\
\cline { 2 - 3 } Initial OxyContin (3 Year Effect) & -0.815 & -0.659 & -0.836 & -0.18 & 1.204 & 0.661 \\
& $(1.624)$ & $(1.595)$ & $(1.618)$ & $(1.584)$ & $(1.412)$ & $(2.314)$ \\
Mean of Dep. Variable (2008-09) & 5.192 & 5.192 & 5.192 & 5.012 & 4.895 & 6.262 \\
Number of Observations & 306 & 306 & 300 & 300 & 288 & 78 \\
\hline
\end{tabular}

Notes: *10\% Significance, **5\% Significance, ***1\% Significance. Standard errors in parentheses adjusted for clustering at the state-level. State fixed effects, year fixed effects, and additional covariates are included in all specifications. Each model also includes a linear trend interacted with initial nonmedical OxyContin misuse as well as a post-2011 indicator interacted with initial nonmedical OxyContin misuse. Finally, a separate post-2011 linear trend interacted with initial nonmedical OxyContin misuse is also included. We report the 3 year post-2011 effect of the initial OxyContin variable. Regressions are weighted by population. "No Pill Mill States" means that Florida, Kentucky, and West Virginia are excluded. "West Only" means that only states in the West Census Region are included in the sample. 